\title{
LARGE MAMMAL BIOMASS PREDICTS THE CHANGING DISTRIBUTION OF HUNTER-GATHERER SETTLEMENTS IN MID-LATE HOLOCENE ALASKA
}

Andrew H. Tremayne and Bruce Winterhalder

Andrew H. Tremayne, Department of Anthropology, University of California, Davis, 328 Young Hall, One Shield Ave. Davis CA 95616 and National Park Service, 240 West 5th Ave. Anchorage, AK 99501 (current address) (andrew_tremayne@nps.gov). *Corresponding author.

Bruce Winterhalder, Department of Anthropology, Professor Emeritus, University of California, Davis 328 Young Hall, One Shield Ave. Davis CA 95616; (current address)825 N 10 ${ }^{\text {th }}$ St, Coos Bay, Oregon 97420 (bwinterhalder@ucdavis.edu).

(C) 2016. This manuscript version is made available under the Elsevier user license http://www.elsevier.com/open-access/userlicense/1.0/ 


\begin{abstract}
This study provides an ecological explanation for the distribution of Arctic Small Tool tradition (ASTt) settlements in Alaska and the origin of their arctic maritime adaptation. Theoretically grounded in the ideal free distribution (IFD) model, which predicts that higher ranked habitats will be occupied first and most continuously, we contendthat the location of large mammals was a major factor influencing human dispersal and settlement decisions in the arctic and subarctic ecosystems of Alaska. We rank habitat suitability based on historic mammal population densities from wildlife ecology reports across predefined ecological zones in Alaska; wemultiply densities by average animal weights per species to determine suitability rankings.Coastal habitats in Alaska are higher ranked than adjacent tundra habitats, but the interior boreal forest may have been the highest ranked, considering technological constraints of hunting aquatic species. The ASTt migration into Alaska created population pressurethat promoted the colonization of the unoccupied Arctic coast and development of the dual, terrestrial-maritime economy. When pan-Alaskahuman populations declined around 3200-2500 years ago low ranked tundra ecoregions were abandoned. As human populations recovered Alaska coasts became the most densely populated habitats.The adaptive logic entailed in the IFD provides a consistent evolutionary interpretation for settlement patterns documented in this region.
\end{abstract}

Key Words: Human behavioral ecology; Population ecology; Ideal Free Distribution; Settlement archaeology; Alaska prehistory; Arctic Small Tool tradition;Maritime adaptations 
Archaeologistsroutinely recognize relationshipsamong resource distribution, adaptive strategies, and prehistoric settlement patterns (Bettinger and Baumhoff, 1982;Binford, 1980; Jochim, 1991; Winterhalder, et al. 2010). Many have drawn on environmental and ecological variables toreconstruct settlement and subsistence patterns for prehistoric cultures of Alaska(Clark, 1984; Dumond, 1987a; Mason and Gerlach, 1995; Potter, 2008a; Yesner, 1981) andarchaeological traditions have been linked to particular habitats (e.g., Dixon, 2013; Dumond, 1987b; Esdale, 2008). This work has demonstrated an uneven distribution of populations through time and delayed settlement of some ecological niches, including the arctic coast.This provokes two central questions: Why were some habitats chosen over others? And, what drove the settlement of previously uninhabited areas?The availability of resources almost certainly played a role in these processes. We have lacked,however, an explanatory framework that integrates considerationsof resource availability, subsistence technology and economics, and human impacts.The goal of this studyis to understand theecological conditions that promoted the initial settlement of the Arctic and the development of maritime adaptations in northern Alaska in just those terms.

The first culture to make routine use of arctic coastal habitats in Alaska was people of the Arctic Small Tool tradition (ASTt) (Ackerman, 1998). The ASTt are thought to be a colonizing population that arrived in Alaska from Siberia around 5000 years ago (Powers and Jordan, 1990; Prentiss et al., 2015; Raghavan et al., 2014; Tremayne and Rasic, 2016). Theyare widely recognized as the first to colonize the high Arctic of North America and Greenland(Dumond, 1987b; Friesen and Mason, 2016; Maxwell, 1980; McGhee, 1996). To understand the ASTt colonization of the Arctic and development oftheir novel economic system we require a method to compare between the qualities of habitats they were willing or able to settle. To do this we developed an ecological model that uses large mammal biomass to predict where newly immigrant ASTt people should have settled first, given the ecological constraints and opportunities facing them.In doing so we demonstrate the interpretive power of behavioral ecology for understanding complex archaeological problems at even the broadest scales. 


\section{Background}

Alaskan researchers typically characterize the ASTt economy as terrestrially basedcaribou hunting with a secondary emphasis on hunting small marine mammals(Ackerman, 1998; Anderson, 1988; Dumond, 1982, 2001; Giddings, 1964; Workman and McCartney, 1998). Recent interpretations give greater emphasis to the importance of ASTt maritime adaptations (e.g., Dixon, 2013; Tremayne, 2015c), although uncertainty on the topic persists.In the eastern Arctic,the ASTt focus on marine resources is more apparent in the archaeological record, although caribou and musk ox were also important to their economy(Grønnow, 1994,2016; McCartney and Helmer, 1989; Melgaard, 2004; Milne and Park, 2016; Møbjerg, 1999; Savelle and Dyke, 2002). At some stage along their migration from Siberiathe ASTt became adept maritime hunters, their dual marine-terrestrial subsistence strategy helping to fuel their spread into Alaska and their migration east. One of the primary goals of this study is to explain why this adaptation emerged when it did and the role access to resources played in this process.

The ideal free distribution (IFD) model from behavioral ecology (Fretwell and Lucas, 1969; Sutherland, 1983) provides an excellent framework for analyzing regional settlement patterns of migratory populations such as the ASTt.Developed first to describe the dispersive behavior and distribution of birds (Fretwell and Lucas, 1969), the IFD has recently proved useful for explaining anthropological problems as well (Codding and Jones, 2013; Jazwa et al., 2013; Kennett et al., 2006; O'Connell and Codding, 2014; Winterhalder et al., 2010). The model posits that dispersive organisms will choose to locate first in the most suitable habitat available. Suitability includes such factors as access to resources, livability, and exposure to hazards (Winterhalder et al., 2010:471). Habitat suitability is typically assumed to be negative density dependent, meaning that suitability is reduced with increased population density and competition for resources. As suitability of the highestranked habitat declines, it eventually equals the next highest ranked (Figure1). Once this threshold is crossed, new arrivals should distribute themselves into the highest ranking and nextranked habitat in a manner that keeps their suitabilities equal.The IFD model posits an equilibrium at which no organism has an incentive to relocate, 
providing us with several predictions: 1) higher ranked habitats should beoccupied first and more continuously through time;2) lower ranked habitats will be occupied in order of their suitability; 3) population density will be greatest in higher ranked habitats; 4) suitability will be equalized across occupied habitats; and 5) suitability declines across all occupied habitats as population grows.

In addition to these basic IFD predictions, the model allows us to take account of territorial or resource defense behavior of competing groups, economies of scale or Allee effects, technological capabilities and innovation, and environmental or other density-independent factors affecting suitability. The IFD model assumesthat individuals are free to move to the highest-ranked habitat available. If mobility is constrained by the competitive or territorial behavior of conspecifics,resource defense inducesthedynamics of ideal despotic distribution (IDD) (Codding and Jones, 2013:14569; Kennett et al., 2009).We follow evolutionary biologists in defining a despotic distribution narrowly as one in which one or more individuals or groups in the population is able to sequester and control a disproportionately large share of the factor or factors determining habitat suitability. Access to a territory and its resources would be an example.Subjugation of one class by anotherthat limits access to resources or the ability to relocate to an area with higher effective suitability (Bell and Winterhalder, 2014) also implies an IDD.

The Allee effect arises if suitability increases with population density over some range (Allee and Bowen, 1932; Kennett et al., 2006; Winterhalder et al., 2010). Population growth from small beginnings may engage economies of scale that raise per capitahabitat suitability as it becomes easier to locate mates, coordinate complex social organization, implement demanding technologies,or gain efficiencies from the division of labor. Presumably there is a population density at which these benefits are exhausted.

A third factor that could affect basic IFD predictions is innovation in technological capability of the dispersing group.Habitat suitability rankings for subsistence are a function of harvesting and processing techniques; they will change if, for instance,an innovative technology transforms a marginally productive environment into a more attractive place to settle. Developments in projectile weaponry, plant processing techniques, fishing and other mass capturing equipment have altered the efficiency with which people have exploitedparticular habitats since the Upper Paleolithic (e.g., Stiner et al., 2000). Myriad 
factors affect technology development and the effectiveness of resource extraction(Bettinger et al., 2006; Tushingham and Bettinger, 2013; Ugan et al., 2003), but innovations are generally made to provide solutions to a resource imbalance.

Finally, density-independent environmental change can modify basic habitat suitabilities, perhaps altering the order in which they are ranked (Jazwa et al., 2013), a factor that potentially looms large in long-term studies such as this one. On a shorter time scale seasonal fluctuations in animal population densities and availability alter suitabilities on an annual cycle, adding short-term dynamics to IFD predictions.

We develop an IFD model that ranks major Alaskan habitats, holding technology and environmental change constant.Our first challenge is deciding which factors are most important for ranking habitat suitability. Other studies have used watershed size and resource base (Winterhalder et al., 2010), effective moisture (O'Connell and Codding, 2014), and environmental bio-productivity (Codding and Jones, 2013) as proxy measures for suitability. Here, we assess suitability by using large animal population densities. We contend that animal products—-particularly meat for food, and skins and bones for clothing and technology—were essential for survival in arctic and subarctic settings.Typically, diet selection models find that prey rank correlates with animal body size (Broughton et al., 2011; Byers and Ugan, 2005; cf. Bayham, 1979; Bird et al., 2009).Furthermore, plants make up a proportionally small part of the diet for most arctic and sub-arctic hunter-gatherer populations (Draper,1977; Searles, 2002).If, in general, large mammalsare highly ranked and known to make a major contribution to diet and raw material resources, then the distribution of these animals should be a significant factor in hunter-gatherer habitat selection and settlement decisions.

Alaska is uniquely suited to studies involving wildlife ecology, as it encompasses large areas with low human population density and relatively pristine wilderness. Decades of wildlife research and management have assessedhabitat-specific animal population densities and monitored seasonal migration patterns. Wildlife conservation laws have also allowed for the recovery in modern times of animal populations threatened in the historic period by overexploitation. Animal populations can 
naturallyfluctuate in size, often dramatically, and management of certain species has led to increased population sizes and recent range expansions (e.g., moose). We argue, however, that presentdayanimal populations represent an adequate baseline estimate for prey population densities during the mid-late Holocene study period. We know these habitats can support at minimum these observed populations densities.

While climate in Alaska has fluctuated between cool/wet and warm/dry periods (Barclay et al., 2009; Calkin, 1988; Clegg et al., 2010; Clegg and Hu, 2010), the major ecological zones defined by modern plant regimes were in place by approximately 6000-4000 years ago (Anderson et al., 2001; Anderson and Brubaker, 1994;Brubaker et al., 2001; Jordan and Krumhardt, 2003; Mason and Bigelow, 2008). We assume the animals that occupy these ecological zones today also occupied them in the past. Zooarchaeological studies across Alaska offer broad support for this assumption (Casperson, 2012; Clark, 1998; Crockford and Frederick, 2007; Giddings, 1964; Larsen, 1968; Potter, 2008b; Schaaf, 2015; Shirar, 2009; Stanford, 1976; Stephenson et al., 2001; Tremayne, 2011; Yesner,1989). We recognize that some areas experienced greater environmental instability,primarily due to volcanic activity (e.g., southwest Alaska), but the presence of sites in these areas throughout our study window suggests animal and human populations always recovered to reinhabit impacted areas relatively quickly, notwithstanding an apparent 500 year hiatus around beginning around 3400 cal BP (Dumond, 2004; Tremayne, 2015b; VanderHoek, 2009).Assuming that the relative proportion of animal populations observed today was on average similar in the past, we can use this information to identify areas of Alaska that likely supported the greatestestimated large-mammal biomass during the last 5000 years.

\section{Habitat Ranking Methods and Data}

Since animal meat makes up a significant percentage of the diet for hunter-gatherers in northern regions (Draper, 1977; Searles, 2002), and bones and skins were primary resources for tools and clothing, we assume the distribution of high ranked prey was a principle determinant of habitat suitability and thus 
of prehistoric settlement patterns. We measure the available large-mammal biomass per ecoregion by the equation:

$$
\text { Suitability }=\Sigma \mathrm{N}_{\mathrm{i}} \mathrm{kg}\left(\mathrm{P}_{\mathrm{i}} \text { ind } / \mathrm{km}^{2}\right)
$$

Where $N=$ average animal weight in kgper taxoni and $P=$ population density of taxoni, ind per $\mathrm{km}^{2}$. We calculate uncertainty in the suitabilityestimate by multiplying the standard deviation of taxa weight by the standard deviation of the population density estimates. To derive an index value we divide the suitability value by the sum total of the ecoregions represented.

A habitat is defined as a geographically bounded region that can be assigned a unique relative suitability from the perspective of human settlement. In our case, an evaluation of suitability focuses on ecoregions supporting one or more large animal species important to the subsistence ecology of prehistoric Native Alaskans(Nowaki et al., 2002) (Figure2). Micro-habitats existing within each ecoregion were necessarily amalgamated to make the analysis manageable. The coastal habitat is defined here as a $10 \mathrm{~km}$ wide strip of land along the Beaufort, Chukchi, and Bering Seas and the western Gulf of Alaska (Figure 2). A $10 \mathrm{~km}$ buffer was chosenbecause it represents an approximate day's walk to and from the water, if a camp were set somewhat inland. The ecoregion bordering the coastal habitat was used to represent the terrestrial component, while values for marine mammals are those of the sea in which they are found.Marine mammal habitat was determined through biogeographical studies providing the extent of each species’ range (e.g., Burns, 1970; Harper, 2007; MacDonald and Cook, 2009). We use modern sea-ice limits as a proxy for estimating the seasonal extent of ice-obligate marine mammal species ranges. Werecognize that climate change in the past affected the extent and duration of the ice in a given area (Crockford and Frederick, 2007; de Vernal et al., 2005), and this may have played a role in the short-term appearance and disappearance of ASTt in southwest Alaska coastal areas at different times.

To rank habitats data were collected on all large-bodied mammals above $30 \mathrm{~kg}$ weight (excluding wolves) per ecoregion. Thisincluded average weight, geographical distribution, and estimated population density by season. Population densities are weighted averages across the entire ecoregion. In cases in which specieshave been driven to local extinction (e.g., bison and musk ox), population densities are 
taken from reintroduced herd counts, and only for ecoregions where paleontological and archaeological data show they were clearly present in prehistory. This procedure undoubtedly underestimates the importance of these species to prehistoric hunter economies. We include bears, although they may not have always been perceived as prey; they are dangerous to hunt and are taboo to kill in some northern cultures (Clark and Slocombe, 2009; Hallowell, 1926). Since high bear population densities and individual weightstend to co-occur with rich fishing streams (Hilderbrand et al., 1999), we consider bears a proxy for anadromous fish within this model.

Animal weights were acquired from Nowak (1999, 2003), Reeves et al. (1992) and from the Alaska Department of Fish and Game website (ADF\&G 2014) (Table 1). Typically, adult weights are given as a range, or as an average weight with a maximum and minimum value. To calculate a standard deviation for animal weights we use the "range rule of thumb," wherein the minimum weight is subtracted from the maximum and this value is divided by four. This assumes that the low and upper rangesrepresent roughly two standard deviations below or above the mean, respectively. To be consistent with population density uncertainties, all subsequent calculations use one standard deviation.

Our estimates for animal population densities come from Alaska wildlife census studies (citations in Supplemental Table 1). The Alaska Game Management Units Map was used to determine ecoregion of the animal census studies (e.g., Harper, 2007:i).Marine-mammal population data for seals, walruses, and whales were gathered primarily by marine biologists conducting aerial surveys over the Bering, Chukchi and Beaufort seas. We do not include Baleen whales in this analysis as archaeological data suggest they were not systematically hunted until about 800 years ago (Jensen, 2012; McCartney and Savelle, 1985). Marine mammal population counts are always considered a minimum, although some studies statistically modeled for submerged animals. If population density was not reported, it was calculated by dividing the population estimate by the reported area of study. In cases of multiple, overlapping surveys we used the mean population density of all of the surveys and include in the measurement the standard deviation of these estimates. 
Population densities of terrestrial mammals are determined primarily through aerial surveys and photocensus (e.g., Harper 2007, 2010).We usereported population density values along with the uncertainty of the estimate. If multiple estimatesare reported they are averaged. If only population counts are given this value is divided by total area ofthe survey unit.To account for seasonal migrations, population density values are adjusted to capture the fluctuations in biomass. For example, population density of ice-obligate marinemammalsis lowered during months where ice is absent, just as it is adjusted for caribou in the arctic tundra when the bulk of the herds migrate south of the Brooks Range for winter (Supplemental Table 1). Where available,we use reported seasonal population estimates. If animals are reported absent from an ecoregion during a given season thedensity value is set to zero, and if some animals are known to remain behind, population densities are estimated based on the available details of the animal migration pattern. For some species (i.e., caribou) this admittedly is a convoluted process (see Notes column in Supplemental Table 1).Because few studies report population densities for all seasons we had to make some inferences when adjusting values for seasonal fluctuations.Seasonal suitability rankings also account for fluctuations in body weight as large northern animals typically become leaner in winter and spring (Table 1).

Average population density estimates should not be taken to imply that animals are evenly distributed across their habitat. For instance, migratory animals are commonly found in aggregations (Burch, 2012; Burns, 1970; Harper, 2007). This is true for both terrestrial and marine mammals. Density remains, however, a useful measure of energetic potential for each ecological zone, provided we keep in mind that clustered animals were detectable or migration routes were predictable and associated with seasonal rounds as demonstrated throughoutethnographic Alaska (Burch, 2006; Gubser, 1965; Guemple, 1981; Haynes and Simeone, 2007; Nelson, 1969, 1973).

\section{Results of the Suitability Rankings}

Basic suitability indexes by season and yearly average are provided in Table 2. Estimated uncertainties built into the model make it impossible to definitively rankecoregionsadjacent on the scale 
by their average values. Nonetheless, high ranking habitats can be clearly differentiated from middle and low ranking ones (Figure 3). Consideringannual averages, the South Bering Coastis the highest rankedecoregion, followed closely by the ChukchiCoast and the Interior Boreal.Allowing for weight and density uncertainties, the top three ecoregions are more-or-less equal in terms of averagelarge mammal biomass, although the Interior Boreal ecoregion has the lowest seasonal fluctuation (Table 2).

The Brooks Tundra, Gulf of Alaska Coast, North Bering Coast, and Beaufort Coastall rankwithin the second tier. We note that five of the top seven habitats are on the coast. The lowest ranked habitats are the Polar Tundra, Bering Tundra, and the Bering Taiga. Of the tundra zones, only the Brooks Tundra ranks highly on an annual average basis, primarily due to the massive aggregations of caribou that funnel through the mountainpasses in the spring and fall.The Bering Tundra, the primary ecoregion for most of the Seward Peninsula, and the Polar Tundra ofnorthern-most Alaska are the lowest ranked ecoregionsdue to their low mammal biodiversity, entailing few large species to hunt when caribou are absent. It must be emphasized that even the lowest ranked habitats can rank highly on a seasonal basis (Table 2), creating incentives to occupy and exploit these habitats when suitabilities temporarily increase.

\section{Archaeological Test Methods and Data Acquisition}

The IFD model assumes thateffective habitat suitability is population density dependent. To analyze settlement patterns in Alaska during the mid-late Holocene it is necessary to understand panAlaska population size trends; were populations increasing, decreasing or at equilibrium?One way to address this question is through an analysis of dated archaeological components. Using this approach, we test two key hypotheses derived from the IFD model. Using our earlier numbering, these are: 1) the highest ranked habitats are occupied first and most continuously through time, and 3) population (site) density will be greatest in higher-ranked habitats.

\section{Radiocarbon Dated Archaeological Components as Proxy for Population Size}

To analyze the timing of occupations per ecoregion we compiled a database of 775 Alaska radiocarbon dates between $6000-1000{ }^{14} \mathrm{C}$ years BP subdivided by culture and ecoregionusing the 
Canadian Archaeological Radiocarbon Database (CARD) (Gajewski et al., 2011), the Alaska Historic Resources Survey (AHRS, 2013) database, reports on file with the National Park Service, and new research into ASTt settlement patterns in Alaska (Tremayne, 2015b: Appendix D)[Supplemental Data Table 2].Only terrestrial based materials from anthropogenic contexts were included in the dataset; dates from marine-based organisms (e.g., shell, marine mammals, fish), and paleontological and geoarchaeological contexts were excluded.

To identify population trends in Alaska we use summed probability density (spd) plots created using the sum function in Oxcal 4.2(Bronk Ramsey and Lee, 2013).After calibration, the spds were exported to Excel, where values were normalized to integrate to one and graphed.Spds are a subset of temporal frequency distributions which combine the probability densities of individual or averaged calibrated dates into one single plot (Brown, 2015; Williams, 2012). The method assumes that the larger the population size the greater the probability a datable event was created in the archaeological record (Brown, 2015; Rick, 1987; Surovell et al., 2009; Williams, 2012). Thus the higher the peak in the spd plot the greater the probablity that population was large at that point in time.To account for possible researcher bias we adjust to weighted averages of dates per component (Ward and Wilson,1978),obtaining a sample of 660 dated components. Component here is defined as a culturally distinct stratigraphic layer or occupational event; many sites in our dataset have multiple components represented. Unfortunately, discrete occupation events are rarely definable (Jochim, 1991:308) and radiocarbon dating resolution does not always permit differentiation betweenpalimpsests of occupations at a given location. Therefore, a chisquare test of compatibility was calculated for each set of dates that were averaged. Outliers were identified and assigned as a separate occupation within a given component.We did not adjust for potential taphonomic bias (Surovell et al., 2009), as we demonstrate elsewhere the correction had little effect on the shape of the spdsat this time scale (Tremayne, 2015b), and because some of the ecoregions in Alaska, particularly the Interior Boreal forest, shows evidence for reduced preservation of organics in younger sites due to acidic soils (Potter, 2008b). 
Spds require sample sizes of at least 300-500 dates to be considered statistically robust as a proxy for population size (Brown, 2015; Williams, 2012). Consequently, we focus on population fluctuations for the entire pan-Alaska sample, and for major sub-groupings that maintain large radiocarbon sample sizes. The radiocarbon data was sub-divided by archaeological culture, coastal versus interior, for only the interior ecoregions with all northwest tundra areas combined, and for all coastal areas with the Beaufort and Chukchi combined into Arctic coasts and the North and South Bering Coasts combined. This allows us to identify geographic areas and ecoregions where populations increased, remained consistent, or decreased.

To determine if ASTt migrants settledthe higher ranked habitats first, we use the phase function in Oxcal 4.2 to construct a Bayesian model of the earliest probable start dates for this culture in each ecoregion.The Bayesian model takes into consideration the probabilities of all of the datesin a dataset and incorporates the uncertainties of each into the estimate (Bronk Ramsey, 2009; Buck et al., 1996). Our sample includes147radiocarbon dates from 43 ASTt sites across Alaska.We have excluded from analysis several of the oldest ASTt dates (Giddings, 1964; Harritt, 1998), now considered unreliable (Tremayne, 2015b; Tremayne and Rasic, 2016).

\section{Archaeological Site Count Data}

Site counts and location data come from the Alaska Historic Resources Survey (AHRS, 2013); they are grouped by major mid-Holocene archaeological traditions(Anderson, 1988; Clark, 1998; Dixon, 2013; Dumond, 1987b; Giddings and Anderson, 1986)and ecoregion. If a site has multiple cultures represented it was counted once for each culture present. The major traditions found in our study area include the Northern Archaic, the Ocean Bay and Kachemak traditions of coastal southern Alaska, the AST tradition, the Norton tradition, the Northern Maritime tradition, and the interior-based Athabaskan tradition. Northern Maritime sites are subdivided between prehistoric (Old Bering Sea, Birnirk, Thule) and historic groups (Iñupiat, Yup’ik, Alutiiq). Sites listed as Athabaskan are sorted by prehistoric and historic groupings as well. We consider young Northern Archaic, late Denali complex, and Kavik phase assemblages to be early Athabaskan (Potter, 2008b:191).ThePaleo-Aleut tradition of the Aleutian 
Islands(e.g., Davis and Knecht, 2010) are omitted because they areperipheral the study area, as are cultures from southeast Alaska.

\section{Calculation of Site Densities}

To estimate site densities we divide site count per archaeological culture by the total $1000 \mathrm{~km}^{2}$ for each ecoregionusing ArcGIS 10.2 for the area determination. While calculation of site counts per ecoregion is straight forward, there is potential for error in cultural assignments and calculation of ecoregion areas. For this reason we estimated site density standard deviations by dividing the square root of site counts by the total area for each ecoregion.Sites from the Mountain Transition ecoregion of south central Alaska were grouped with the Interior Boreal forest count. Ecoregion areas were calculated using the sum polygon feature in ArcGIS 10.2; the peaks of the Alaska Range above approximately 9000 feet were omitted from the total area estimate for the Mountain transition ecoregion, as they are permanently covered in snow. We use a $10 \mathrm{~km}$ wide buffer to calculate the area of coastal zones and divide the North and South Bering Coast at the mouth of the Kuskokwim River.St. Lawrence Island is included with theNorth Bering Coast and Nunivak Island with the South Bering Coast. We did not include the Aleutian Islands in the South Bering Coast estimate which also was bounded at the tip of the Alaska Peninsula. For the Gulf of Alaska we calculated area for all of the coast and islands of the western Gulf of Alaska, including Kodiak. The east side of theKenai Peninsula marks the extent of the Gulf of Alaska coast used in this analysis(Figure2). The southeast Alaska coastal rainforest ecoregion was omitted as peripheral to the study area.

\section{Archaeological Test Results}

\section{Population Fluctuation through Time}

The form we have given our IFD hypotheses requires that we demonstrate population size fluctuatedthrough the mid-late Holocene in Alaska. Using our radiocarbon record as a proxy, we find that pan-Alaska populations increased around 4500-4200 cal B.P. (Figure 4A). Subdividing the sample by relative proportion of major traditions shows theNorthern Archaic and Ocean Baypopulations were 
mostly at equilibrium for 2000 years prior to the arrival of the ASTt (Figure 4A). The pan-Alaska population increase at 4500 years ago is primarily the result of the ASTt in-migration and rapid population growth rate (Tremayne, 2015b). This is an important observation because it suggests increased population pressure coincident with the establishment of the ASTt in Alaska.

The increase in pan-Alaska population size is seen primarily in southwest and northwest Alaska, while the interior shows evidence of a stable population throughout the mid-late Holocene (Figure 4B). This suggests that the Northern Archaic and subsequent Athabaskan populations had reached carrying capacity prior to the arrival of the ASTt to Alaska, but there was room for growth in both southwest and northwest ecoregions.

Looking specifically at the interior sample we see the bulk of the population growth during the ASTt period was in the tundra ecoregions of northern Alaska (Figure 4C). By contrast, the Interior Boreal populations appear to be more stable through time, while the Bering Taiga of southwest Alaska supportedrelatively small population sizes. The disappearance of the ASTt coincides with theabandonment of the arctic tundra ecoregions including the Polar Tundra, Brooks Tundra and the Bering Tundra of the Seward Peninsula (Figure 4C). The question is whether this population trend represents a population crash or a shift to new territories.

On the coast, population density changesare also observed and more complex to interpret (Figure 4D). The growth observed during the ASTtperiod appears concentrated along the arctic coastlines of the Chukchi and Beaufort Seas, while the Bering Sea coast shows little evidence for sizable populations there until after 2500 cal BP. The Gulf of Alaska is clearly the earliest and most continuously occupied ecoregion of the coastal dataset, although a major population decline occurs in the region at the same time as the rest of coastal and tundra Alaska. By about 2500 cal BP populations recover to approximate precrash levels.As pan-Alaska populations begin to recover,circa 2500 cal BP, there is a clear increase in the relative use of the Bering and Arctic coasts and the further development of maritime economies (Figure 4D). During the subsequent 1000 years of continued population growthwe observe the emergence of the Northern Maritime tradition, the colonization of Bering Sea islands, the establishment of territorial 
boundaries, andthe development of organized whale hunting (Dumond, 1987b; Mason,1998). Meanwhile, the tundra ecoregions fail to recover during the renewedpan-Alaska population increase to pre-crash populations sizes (Figure 4C).

\section{Bayesian Analysis of Initial ASTt Dates}

The model start dates for the ASTt suggest this society first appears in Alaska on the Bering Sea coast around 4995 cal BP, and approximately 300-400 years later along the Chukchi and Beaufort coasts (Table 3) (Figure 5). It is during this time that ASTt influence also becomes evidenton the eastern side of the Alaska Peninsula and western Gulf of Alaska, including Kodiak Island (Steffian and Saltonsall, 2005; Workman and Zollars, 2002). The model start dates for inland settlements postdates ASTt presence along the coast by many centuries, beginning by $4365 \pm 65$ cal BP (Figure 5). ASTt peoples settled coastal ecoregions first in all casesexcepttheNorth Bering Coast, unless the oldest Iyatayetand Bering Tundra dates are demonstratedvalid (see gray plots in Figure5).

Comparing modeled date means against the suitability index demonstrates that ASTt peoples settled the highest rankinguninhabited habitats first, and there is a general trend toward later startdates in the lower ranked habitats (Figure6). These results generally confirm our first hypothesis,with exceptions requiring discussion.First, as we might expect, there is evidence of delayed entry into the highly ranked but occupied Interior Boreal and the Brooks Tundra ecoregions. These areas were part of theNorthern Archaic territory when ASTt arrived from Asia. Also somewhat anomalous is the northern Bering Coast.The delayed start date in this ecoregion is harder to explain as there is clear evidence theASTt is present along other coastal areas of Alaska by this time. We hypothesize that this exception is a sampling problem, as there is a lack of archaeological investigations in this area and only 12 reliable dates in our sample. In fact, all of the dates used for the north Bering Coast estimate are from one site, Iyatayet.If we includethe suspect earliest dates from Iyatayet (Giddings,1964), there is a chance this area was occupied first by ASTt people; however the posterior modelhas very high uncertainty (see gray plots in Figure 5). Assuming the ASTt arrived from Siberia to the Seward Peninsula first, we expect to find the oldest ASTtsites in this area;unfortunately, the data we have in support of this scenario lacks precision and 
accuracy in both the calibrated dates(see gray plots in Figure 5) and their archaeological contexts (Harritt, 1998).

\section{Site Frequency and Density per Ecoregion}

According to the AHRS (2013), a total of 22,850 sites are found in our study area, from the earliest occupations up to historical contact. Filtering by cultural affiliation for the societies in our studygenerates a sample of 5366 sites from a mid-late Holocene context. In general, the frequency of sites per ecological zone becomes more evenly distributed across ecoregions through time (Table 4). Nearly 90\% of Northern Archaic sites are found in the Interior Boreal ecoregion and the Brooks Tundra (Table 4). Northern Archaic peoples rarely occupied the coast, although there is evidence from seven sites that indicate occasional use of coastal habitats. Based on associated faunal remains it has been argued they were engaged in caribou hunting at these sites, although it is feasible they were actively experimenting with a maritime adaptationnew to them (Esdale, 2008). The early Ocean Bay and descendent Kachemak traditions are found almost exclusively along the Gulf of Alaska and Kodiak Island (Table 4). These cultures had a fully adapted maritime economy that made use of all marine and terrestrial resources (Clark, 1998, 2001).

ASTt sites are more evenly distributed between ecoregions, but their counts are lowest in areas that were already occupied by NorthernArchaic and Ocean Bay people, and in the lowest ranking ecoregions (Table 4). Based on site count alone, ASTt spent a great deal of time in the Brooks Range and Polar Tundra. Even the lowest ranked ecoregions can rank high on a seasonal basis (Table 2). When Norton culture appears around 2500-3000 years ago their settlement patterns mirror the ASTt, but with an increased presence in the South Bering Coast.Norton sites in the Interior Boreal forest andGulf of Alaska Coast are rare, as there remain early Athabaskan andKachemak tradition populationsin these areas. TheNorthern Maritime tradition sites are primarily foundin northern Alaskaalong the Bering and Chukchi Coasts (Table 4).Sites identified as Inuit (Iñupiat, Yup’ikand Alutiiq) are evenly dispersed throughout all ecological zones,with the exception of the Interior Boreal where Athabaskans persist(Table 4). 
Toestimate human population pressure and settlement/occupation intensity we also calculate site density by culture per ecoregion (Table 4). Using every site with coordinates found in the AHRS (2013) site records $(n=22,850)$, irrespective of culture or time frame, the highest ranked habitats have the highest site densities, averaged over the entire span of the Holocene (Figure7A). Even taking the uncertainty of these estimates into consideration,eight of the ten ecoregionsshow a strong trend toward lower site densities in lowerranked habitats. The Gulf of Alaska Coast is a notable outlier, as is the Bering Taiga, to a lesser extent.

Focusing on our filtered sample of mid-late Holocene sites with the ascribed cultural affiliations ( $\mathrm{n}=5366$ ), the results again show higher-ranked habitats have higher site densities through time (Figure 7B). This same trend is observed across all time periods when contemporary cultures are combined into subsets. For example,Figure8Arepresents the Northern Archaic and Ocean Bay period (6000-4000 years ago). As with the pan-Holocene sample, there is a trend of higher site densities in higher ranked areas. The exceptions are the very high densities for the Gulf of Alaska and the lack of sites for this time period in the northern Bering Coast. Adding the ASTt site count to the dataset increases the positive correlation between habitat rank and site density (Figure 8B), a trend that continues for the later groups (Norton, Kachemak, Northern Maritime and prehistoric Athabaskan traditions) (Figure 8C). By the historic period we find all of the coastal areas of Alaska have very high site densities, while the interior ecoregions are considerably lower. Each ecoregion has increasinglyeven distributions between these respective groups (Figure 8D). The implications are two-fold: 1) the coast supports higher population densities than interior, and 2) habitat suitabilities began to equalize as population pressure increased in the higher ranked ecoregions promptingIFD-like dispersals into lower ranked ecoregions.

Looking specifically at ASTt site densities gives us insight into their distribution in light of the suitability rankings and locations of the archaeological cultures that precede them. The highest ASTt site densities are on the Chukchi Coast, the Brooks Tundra and the BeaufortCoast (Figure9). Basedon this model, ASTt should have higher site densities in four ecoregions, in rank orderhigh to low: the South BeringCoast, the Interior Boreal forest, the Gulf of Alaska coast and the North Bering Coast (dashed 
circle, Figure9).As mentioned, the Interior Boreal forest is occupied by Northern Archaic people, and the Gulf of Alaska coast by Ocean Bay tradition people (Odess, 2005; Steffian and Saltonsall, 2005).Preexisting occupation would result in a reduced effective suitability of these two habitats to newcomers, competition depreciating their attractiveness for settlement relative to the basic suitabilities that inform our predictions. Adding Northern Archaic and Ocean Bay sites, as shown in Figure 8B, increasesthe site densities of the Interior Boreal and Gulf of Alaskaecoregions, significantly improving the expected model correlation. Still lacking, however, is an explanation for the relatively low ASTt site densities along the high ranked North and South Bering Coasts. Limited technological access to maritime resources, lack of intensive archaeological survey in these regions, or site loss due to coastal erosion and rising sea level might help to explain this anomaly. That we find the earliest ASTt sites on the coast in these areas suggests additional occupations are missing or undiscovered, or alternately that these early traces are due to limited cultural transmissionand trade with other southwest populations but not to settlement.The evidence suggests southwest Alaska and the Aleutians supported three distinct cultures during midHolocene period just prior to the ASTt appearance. Why cultural diversity of this area was so high in prehistory requires an explanation. The low number of sites on the South Bering Coast from this time period suggests taphonomy and lack of survey are to blame.

\section{Discussion and Implications}

We examine evidence of ASTt settlement decisions within an IFD framework. Our assumption that arctic and subarctic habitat suitability for humans can be estimated using highranked preybiomass has been well-supported.We acknowledge that there are deficiencies in both the wildlife census studies and

the archaeological record; weaddress these in part by incorporating uncertainty into the key parameters of the model, the population densities and animal weight data.Modeling the areas of Alaska that support the greatest amount of mammal biomass through time has allowed us to identify areas which human populations would have found most suitable for initial occupation, and in which they would have lived in the highest numbers averaged over time. 
Our IFD model does not explain all settlement decisions as, in its simplest form, it neglects other supplementary prey (fish and birds) and other sources of raw material. Other neglected factors like the availability of fuel wood or milder weather (the Gulf of Alaska is significantly warmer than the Arctic coast in winter)are ignored, although they conceivablywereimportant for the timing and intensity of occupations.Nevertheless, our analysis demonstrates the importance of large mammals to prehistoric settlement patterns in Alaska, and does much to explain the initial dispersal of the ASTt migrants.

Consistent with IFD model predictions, mid-late Holocene settlement of Alaska proceeded, in most cases, from high-ranked to low-ranked ecoregions.As population increased, augmented primarily with the continued migrationof ASTt people into Alaskaand/or birthrates greater than replacement (Figure 4A), there is a infilling of populations into the highest ranking, uninhabited ecoregions (North and South Bering Coasts and Chukchi Coast) and subsequently into lower-ranked habitats (Beaufort Coast, Polar Tundra, Bering Tundra) and areas where competition with contemporarygroups would have occurred (Interior Boreal, Brooks Tundra, Bering Taiga). By the late Holocene the range and intensity of habitats occupied began to equalize, measured by settlement density, as population pressure forced people to spend greater amounts of time extracting resources in the most marginal habitats.

Lower ranked habitats, primarily the tundra zones,attracted and were more densely settled by the most recent arrivals to Alaska—-the ASTt and Nortonfollowed by the Northern Maritime (Thule) tradition - while the Interior Boreal and Gulf of Alaska areas show greater historical depth and continuity of recognized social traditions.Links have been made between the Ocean Bay and subsequent Kachemak Tradition (e.g., Clark, 1998) and others have suggested continuity between Northern Archaic and Athabaskans is probable(Esdale, 2008:7; Potter, 2008b:191). While there are lingering debates about Alaska culture history, and undoubtedly some cultural diffusion and intrusive migrations, the territorial boundaries establishedduring the ASTtperiodseem to persist through the historic period. Once in place populations were less likely to give up their high ranking areas. Ecoregions with greater seasonal fluctuations in prey however were more susceptible to seasonal incursions from new or expanding groups. In volcanically active southwest Alaska cultural succession and competition appears higher than other 
ecoregions, suggesting frequent environmental destruction and recovery promoted repeated abandonment and resettlement from adjacent populations (VanderHoek, 2009).

\section{Coast verses Interior Habitats}

Our analysissuggests that the Alaska coast is generally a high-ranked ecosystem based on large mammals, capable of supporting higher population densities than interior habitats. However, at present, evidence for systematic use of maritime habitats in northern Alaska appears to followexploitation of the interior. Yesner (1998) and others (e.g., Workman and McCartney, 1998) have argued that the shift to the coast in southern Alaska at the close of the Pleistocene was prompted by a collapse of large terrestrialmammal populations. Whether this is true or not, the same kind of argument cannot be made for the delayed settlement of the Arctic coast. Instead, our study suggests that population pressure caused by the ASTt migration and technological advancements, either through independent invention or cultural transmission with southwest Alaska maritime populations, made sea mammal hunting in arctic waters more attractive. The population pressure that promoted the arctic maritime adaptation may have actually occurred on the Asian side of the Bering Strait, and the dispersal of the ASTt into Alaska may have simply been the settlement of the highest ranking, uninhabited ecosystem available.

The observation that coastal adaptations post-date interior terrestrial onesin Alaska supports arguments that maritime hunting is more labor intensive and technologically expensive than hunting terrestrial game. People who make a living from aquatic habitats typically have a more complex hunting technology (Oswalt, 1976; Yesner, 1980), in order to reach and to forestall prey escaping beneath the water or ice. Boats are required along with hunting technology with a line attached to it (e.g., toggling harpoons, line and hooks, and nets). Because maritime resources are technologically expensive and perhaps more dangerous to hunt, foragers who can make an adequate living by instead hunting terrestrial game probably will do so. This seems to be the case for Northern Archaic people. Despite having the opportunity to exploit the rich maritime resources of the Bering and Chukchi Seas, Northern Archaic people opted to seasonally exploit resources from lower ranked inland habitats instead (e.g., Brooks and 
Polar Tundra and the Bering Taiga). The implications are that Northern Archaic lacked the technology or know-how to effectively exploit marine ecosystems and were conservative in their economic adaptations.

This,however, is not the case for the ASTt. Our analysis shows they must have possessed a sophisticated maritime adaptation at the outset of their migration into Alaska and across the Arctic. A lack of preserved fauna and organic technology from coastal ASTt sites has generally hampered investigation of this point, but recent work along the Chukchi Coast in northwest Alaska has provided support of ASTt marine mammal exploitation at least by $4500 \mathrm{cal}$ B.P., evident in the form of preserved lipids encrusted in beach sands (Buonasera et al., 2015; Tremayne, 2015c).

We are implying here a modification to our basic IFD assumptions: When the cost and effectiveness of technologyis factored into effective suitability assessment, the Alaskan interior might have been higher ranked than the coasts. Our inability to precisely estimate the population densities of extinct mammals such as bison and elk have probably led to underestimates of the suitability of this ecoregion.However, with specialized technology the coast can support higher population densities.The low population densities in the interior compared to the coast (Figure 8D), but earlier and continuous use of this habitat (Figure 4B), support this interpretation.

We also show that coastal population densities increased over time while interior population densities were mostly stable (Figures 4C and 4D).Coastal habitats apparently provided abundant opportunities to increase foraging efficiencythrough the development of techniques to capture a larger variety of prey. Interestingly, we speculate that coastal suitabilities may have increased with larger population sizes and the economies of scale they allow, demonstrating an Allee effect. This is consistent with the observation that exploitation of large marine mammals requires cooperative hunting strategies.

Once the northern coastal populations were established they were also more stable than in adjacent areas. For example, the pan-Alaska population decline at 3400-2700 cal BP is most pronounced in the tundra zones. As caribou were by far the primary resource for people occupying tundra habitats, we concur with others who have proposed a caribou population collapse occurred at this time (Dumond, 
1987b; VanderHoek, 2009). VanderHoek (2009) has built a solid casethat the caldera-forming Aniakchak II eruption prompted widespread ecological destruction and decline of the Western Arctic caribou herd.

In general, the tundra zones are the riskiest, in terms of stability and predictability of resources, for all of Alaska.Settlements in the Brooks Range for example were most likely seasonal camps from established coastal or boreal forest populations. Year round occupation of the Brooks Range was probably limited in prehistory, as suitability is reduced significantly in seasons in which caribou are not present. When caribou populations were large, hunters followed herds back and forth through the Brooks Range (Rasic, 2008; Tremayne, 2015a), but when caribou populations crashed, hunters abandoned the Brooks and Polar tundra ecoregions for the coast.Ethnohistorical accounts document the return of the Nunamiut to the mountains from the coast after a period of abandonment in the early $20^{\text {th }}$ century due to lack of caribou (Gubser, 1965:240).Absent the migratory herds, Alaskan foragers moved to the coast where resources were more stable.

The Ocean Bay occupations on the Gulf of Alaska coast may be an exampleof a settlement system not driven primarily by large-mammal prey populations. The archaeology suggests our IFD model should rank the Gulf coast as the highest ranked habitat. People of the Ocean Bay tradition are present at the outset of the study period and their descendants produce the highest site densities throughout the Holocene, but large-mammal density is relatively low. We see two plausible explanations for why our model under-ranks the Gulf of Alaska coast. They perhaps acted in combination: 1) marine mammal populations are lower today than they were in the past; or 2) smaller but perhaps not lower ranked prey items, (e.g., anadromous fish, marine fish, shellfish, birds) entered the dietbreadth, occurring in high enough densities thatthey had a large influence on settlement patterns. Consistent with the first, since the 1970s marine biologistsworking in the Gulf of Alaska and southern Bering Sea have documented population declines for sea lions, seals, and sea otters of 50-70\% (Boveng et al., 2003; Burn and Doroff, 2005; Estes et al., 2009; Jemison et al., 2006; Sease and York, 2003; Small et al., 2008; Yen et al., 2005).In support of the second explanation, however, is the faunal record at Ocean Bay sites, which 
shows fish, shellfish and birds were major dietary components throughout human history in the Gulf of Alaska (Casperson, 2012; Clark, 1998, 2001).

\section{Implications for ASTt Settlement and Maritime Adaptations}

The dynamics that led to the ASTt settlement of the Bering, Chukchi and Beaufort coasts could in part reflectan ideal despotic situation, as the Northern Archaic and Ocean Bay people deflected the immigrant ASTt people away from territories they occupied(Interior Boreal and Gulf of Alaska Coast).Defense of an occupied habitat, high in its basic suitability, detracts from its effective suitability to an outsider. Site density data and the timing of ASTt settlementsgenerally corroborate this interpretation. This of course assumes the initial ASTt colonizers were able to explore every ecoregion, coastal and interior, within a very short timeframe.Suggesting caution, however, is the fact that we have no confirmation that contact between Northern Archaic and ASTt was hostile. In fact there is very little evidence for interaction between these groups, outside of the extensive use of obsidian from the Batza Téna source locate well within Northern Archaic territory. Signs of ASTt interaction with Aleutian and Ocean Bay culturessuggest friendly relations, as there is evidence for cultural and genetic transmission between groups (Davis and Knecht, 2005; 2010; Gilbert et al., 2008; Maschner et al., 2010; Steffian and Saltonsall, 2005). Rather than being excluded from high ranking areas due to territoriality, the ASTt movement into unoccupied habitats might be better explained by population pressure and lowered effective suitability in occupiedecoregions, and the fact that the Chukchi coast where they would have first arrived was an unoccupied, high ranked niche.

Afocal question in this analysis has been: where did ASTt first settle in Alaska and why did they choose these areas? We have provided archaeological evidence and behavioral ecology interpretation that initial ASTt peoples spread first into habitats along the coast. Based on our analysis of the current, mostreliable radiocarbon dates, the ASTt peopleappear first inthe southern Bering Coast at the tip of the Alaska Peninsula (Maschner et al., 2010). Within a few centuries they are present along the Gulf of Alaska, the Chukchi and Beaufort Coasts (Figure 5).Researchers working the high Arctic of central Canada have documented ASTt sites (Pre-Dorset) older than any found to date in Alaska (Savelle and 
Dyke, 2002).Using 45 early ASTt radiocarbon dates from Savelle and Dyke (2002), excluding one date of $5245 \pm 42{ }^{14} \mathrm{C}$ year BP on spruce driftwood and all dates on shell,the Bayesian modeled start date for ASTt on Victoria Island is $5183 \pm 45$ cal BP. This is almost 200 years older than the earliest modeled date for Alaska. Ifthe ASTt truly represents a migration out of Asia across the Arctic (Raghavan et al., 2014), then the very oldest ASTt occupationsin Alaska have yet to be found or confirmed with reliable dates. One possible explanation for thisincongruity: the low sediment depositional environment of the high-Arctic is possibly better suited for locating and identifying early archaeological sites than the coastal environment in Alaska, where sediment deposition on the coast is generally pronounced.

Archaeologists have argued that the coast is easier for Holocene migrants to colonize than the interior of continents (Erlandson, 2001; Erlandson et al., 2007; Yesner, 1980). Coastal habitat allows for a one-dimensional or linear settlement pattern that follows a relatively homogenous and continuous ecological niche. This is contrasted with a planar settlement pattern that crosses many ecoregions and potentially challenging geographic barriers (Erlandson et al., 2007; Yesner, 1980). Assuming technological proficiency, our IFD application to Alaska demonstrates that most coastal habitats are more productive of high-ranked prey than their adjacent interior tundra and forest habitats. Logistical or seasonal forays inland would have allowed both sets of resources to be exploited. Whether or not the coast is actually easier to settle than interior habitats is debatable, but the data we have indicates the initial ASTt colonization followed a linear settlement pattern along the coast, both south and northeast into Canada. We argue this was facilitated by the availability of both high-ranking marine-mammal and terrestrial prey. This pattern suggests the ASTt founding population possessed maritime hunting skills from the outset of the colonization process. The implications are theirmaritime adaptation originated in Asia, which is logical since a crossing of the Bering Strait was prerequisite to reaching Alaska.

The problem with this scenario is that no solid evidence for a coastally adapted ASTt culture has been found in Chukotka(Ackerman, 1998). The earliest evidence for maritime adaptations on the westernside of the Bering Strait is about 3400 years BP(Dikov, 1988; Orekhov et al., 1998). However, as with Alaska, the earliest evidence could be submerged. Sea level probably stabilized in the Bering Strait area 
around 6000 years ago (Mason and Jordan, 2001), thus there could be older Bering and Chukchi maritime cultures that are presently inaccessible. However, we find at least a 1000 year period between the stabilization of sea level and the appearance of persistent coastal occupations in northwest Alaska, which tends to support the hypothesis that the ASTt migrants were the first to routinely occupy these habitats.Maritime adaptations may have developed rapidly as people spread into the uninhabited arctic coast niche.

Whether the ASTt maritime adaptation was independently invented or adopted and modified from another group is uncertain. What is cleareris that the origin and development of ASTt maritime adaptations occurred very rapidly and within a few centuries they spread everywhere marine mammals could be targetedfrom southwest Alaska to Greenland.Living on the coast does not preclude use of the interior habitats. The ASTt not only targeted terrestrial mammals, but over time some among them became specialized caribou hunters based in Brooks Range (Tremayne, 2015a). The order of these developmentsis crucial, as their maritime adaptations precede the shift to the lower ranked tundra habitats. Our model predictions and data demonstrate that large mammal biomass including marine mammals, along with the location of extant group’s territories,predictably influenced ASTt settlement decisions on their entry into Alaska.

\section{Caveats}

With the goal of identifying habitats in Alaska that were most attractive to the colonizing ASTt population during the middle Holocene, we have focused narrowly on large mammal biomass as the most important environmental factor affected their settlement decisions. The result is positive, but it is a beginning step toward a more thorough accounting of factors affecting habitat suitability. We likewise have generalized by assuming that animal population densities were proportionally similar over the middle to late Holocene. The reliability of this assumption fades the further we go back in time. Some areas experienced greater environmental change in the late Holocene; in other cases we lack sufficient data to determine with assurance if a given species lived in an area or not. Further data acquisition and 
perhaps alternate methods for calculating relative densities of prehistoric animal population through zooarchaeological and paleontological sampling would improve the accuracy of the model for different time periods. Uneven archaeological survey and excavations hampers our ability to interpret the results with the confidence of a fully representative sample. Increased research in southwest Alaska and in some of the lower ranked ecoregions is warranted and would help offset some uncertainty. Taphonomic issues and quality control of big data sets, such as we used from the AHRS and CARD databases, also pose challenges that we expect to diminish with time. Against these potential shortcomings, we note that our model framework is sufficiently general to accommodate modifications and further testing as more and better data become available.

\section{Conclusions}

We develop an application of the IFD model, seeking to explain the cause and timing of ASTt population immigration into and settlement of maritime and interior Alaska during the mid-Holocene. We assess ecoregion (habitat) suitability for ASTt colonizers based on large-bodied mammalpopulation densities and biomass from coastal and terrestrial ecosystems, and we assess the premise of growinghuman population density through an analysis of radiocarbon dated components and site counts per ecoregion. We find that coastal zones of Alaska are generally higher ranked than adjacent tundra habitats, and predict that they should be occupied earlier and more continuously, at higher site densities than lower ranked habitats. With a few exceptions which admit of plausible explanation yet to be tested, the archaeological data on mid-late Holocene cultures in Alaska are consistent with these predictions.

When the ASTt appears in Alaska, the societies it represents settled in the highest ranking unoccupied areas first; they only later move into the lower ranked interior tundraecoregions. The ASTt were virtually absent from the Interior Boreal ecoregion and Gulf of Alaska coast,probably because resident populations lowered the overall effective suitability of these areas for new arrivals. The implications are that ASTt people must have been proficient maritime hunters at the outset of their colonization process, and their dual maritime-terrestrial economy helped fuel their spread into Alaska and 
across the Arctic.Intensive surveys of coastal areas in Alaska, particularly the South Bering Coast in search of ASTt sites should be implemented to further test these hypotheses and predictions.

\section{Acknowledgements}

We owe our thanks to people that have contributed to the completion of this project, including

especially Christyann Darwent, Robert Bettinger, John Darwent, and Kelly Eldridge.Mark Grote provided assistance in developing the model and in the statistical methods used to analyze the data.Thanks to William Brown for his help with the analysis of radiocarbon dates. Thanks to Jeff Rasic and our anonymous reviewers whose comments were both insightful and helpful.Our spouses (Sara Tremayne and Sheryl Gerety) and families have been gracious about our distraction while pursuing this work. National Science Foundation grant \# ARC-1022523 funded fieldwork and data collection. Additional financial support for this project was provided by the University of California, Davis (Anthropology Department),the National Park Service, and the Murie Science and Learning Center Fellowship.

\section{References Cited}

Ackerman, R.E., 1998. Early maritime traditions in the Bering, Chukchi, and East Siberian Seas. Arctic Anthropology 35, 247-262.

ADF\&G, 2014. Alaska Department of Fish and Game http://www.adfg.alaska.gov/.

AHRS, 2013. Alaska Historic Resource Survey. Office of History and Archaeology. Anchorage, Alaska.http://dnr.alaska.gov/parks/oha/.

Allee, W.C., Bowen, E.S., 1932. Studies in animal aggregations: mass protection against colloidal silver among goldfishes. Journal of Experimental Zoology 61, 185-207.

Anderson, D.D., 1988. Onion Portage: An archaeological site on the Kobuk River northwest Alaska. Anthropological Papers of the University of Alaska 20.

Anderson, L., Abbott, M.B., Finney, B.P., 2001. Holocene climate inferred from oxygen isotope ratios in lake sediments, central Brooks Range, Alaska. Quaternary Research 55, 313-321.

Anderson, P.M., Brubaker, L.B., 1994. Vegetation history of northcentral Alaska: A mapped summary of late-quaternary pollen data. Quaternary Science Reviews 13, 71-92.

Barclay, D.J., Wiles, G.C., Calkin, P.E., 2009. Holocene glacier fluctuations in Alaska. Quaternary Science Reviews 28, 2034-2048.

Bayham, F.E., 1979. Factors influencing the archaic pattern of animal exploitation. Kiva 44, 219-235.

Bell, A.V., Winterhalder, B., 2014. The population ecology of despotism. Human Nature 25, 121-135.

Bettinger, R.L., Baumhoff, M.A., 1982. The Numic spread: Great Basin cultures in competition. American Antiquity 47, 485-503. 
Bettinger, R.L., Winterhalder, B., McElreath, R., 2006. A simple model of resource intensification. Journal of Archaeological Science 33, 538-545.

Binford, L.R., 1980. Willow smoke and dog's tails: Hunter gatherer settlement systems and archaeological site formation. American Antiquity 45, 4-20.

Bird, D.W., Bird, R.B., Codding, B.F., 2009. In pursuit of mobile prey: Martu hunting strategies and archaeofaunal interpretation. American Antiquity 74, 3-29.

Boveng, P.L., Bengtson, J.L., Withrow, D.E., Cesarone, J.C., Simpkins, M.A., Frost, K.J., Burns, J.J., 2003. The abundance of Harbor Seals in the Gulf of Alaska. Marine Mammal Science 19, 111127.

Bronk Ramsey, C., 2009. Bayesian analysis of radiocarbon dates. Radiocarbon 51, 337-360.

Bronk Ramsey, C., Lee, S., 2013. Recent and planned developments of the program OxCal. Radiocarbon 55, 720-730.

Broughton, J.M., Cannon, M.D., Bayham, F.E., Byers, D.A., 2011. Prey body size and ranking in zooarchaeology: theory, empirical evidence, and applications from the northern Great Basin. American Antiquity 76, 403-428.

Brown, W.A., 2015. Through a filter, darkly: population size estimation, systematic error, and random error in radiocarbon-supported demographic temporal frequency analysis. Journal of Archaeological Science 53, 133-147.

Brubaker, L.B., P.M. Anderson, F.S. Hu, 2001. Vegetation ecotone dynamics in southwest Alaska during the late Quaternary. Quaternary Science Reviews 20(1-3):175-188.

Buck, C.E., Cavanagh, W.G., Litton, C.D., 1996. Bayesian Approach to Interpreting Archaeological Data. John Wiley \& Sons Ltd., New York.

Buonasera, T., Tremayne, A.H., Darwent, C.M., Eerkins, J., Mason, O.K., 2015. Lipid biomarkers and compound specific $\delta 13 \mathrm{C}$ analysis indicate early development of a dual-economic system for the Arctic Small Tool tradition in northern Alaska. Journal of Archaeological Science 61, 129-138.

Burch, E.S.J., 2006. Social Life in Northwest Alaska. University of Alaska Press, Fairbanks.

Burch, E.S.J., 2012. Caribou Herds of Northwest Alaska 1850-2000. University of Alaska Press, Fairbanks.

Burn, D.M., Doroff, A.M., 2005. Decline in sea otter (Enhydra lutis) populations along the Alaska Peninsula, 1986-2001. Fishery Bulletin 103, 270-279.

Burns, J.J., 1970. Remarks on the distribution and natural history of pagophilic pinnipeds in the Bering and Chukchi Seas. Journal of Mammalogy 51, 445-454.

Byers, D.A., Ugan, A., 2005. Should we expect large game specialization in the late Pleistocene? An optimal foraging perspective on early Paleoindian prey choice. Journal of Archaeological Science 32, 1624-1640.

Calkin, P.E., 1988. Holocene glaciation of Alaska (and Adjoining Yukon Territory, Canada). Quaternary Science Reviews 7, 159-184.

Casperson, M.R., 2012. The importance of birds in Ocean Bay subsistence: results from the Mink Island site, Katmai National Park and Preserve, Alaska. Arctic Anthropology 49, $18-34$.

Clark, D.A., Slocombe, D.S., 2009. Respect for grizzley bears: An aboriginal approach for co-existence and resilience. Ecology and Society 14, 42.

Clark, D.W., 1984. Prehistory of the Pacific Eskimo Region, in: Damas, D. (Ed.), Handbook of North American Indians: Arctic, Smithsonian Institute, Washington D.C.,pp. 136-148.

Clark, D.W., 1998. Kodiak Island: The later cultures. Arctic Anthropology 35, 172-186.

Clark, D.W., 2001. Ocean Bay, in: Perigrine, P.N., Embers, M. (Eds.), Encyclopedia of Prehistory: Arctic and Subarctic. Springer-Verlag, New York, pp. 149-164.

Clegg, B.F., Clarke, G.H., Chipman, M.L., Chou, M., Walker, I.R., Tinner, W., Hu, F.S., 2010. Six millennia of summer temperature variation based on midge analysis of lake sediments from Alaska. Quaternary Science Reviews 29, 3308-3316.

Clegg, B.F., Hu, F.S., 2010. An oxygen-isotope record of Holocene climate change in the south-central Brooks Range, Alaska. Quaternary Science Reviews 29, 928-939. 
Codding, B.F., Jones, T.L., 2013. Environmental productivity predicts migration, demographic, and linguistic patterns in prehistoric California. Proceedings of the National Academy of Sciences 110, 14569-14573.

Crockford, S.J., Frederick, S.G., 2007. Sea ice expansion in the Bering Sea during the Neoglacial: Evidence from archaeozoology. The Holocene 17, 699-706.

Davis, R.S., Knecht, R.A., 2005. Evidence for the Arctic Small Tool Tradition in the eastern Aleutians. Alaska Journal of Anthropology 3, 51-65.

Davis, R.S., Knecht, R.A., 2010. Continuity and change in the eastern Aleutian archaeological sequence. Human Biology 82, 507-524.

de Vernal, A., Hillaire-Marcel, C., Darby, D.A., 2005. Variability of sea ice cover in the Chukchi Sea (western Arctic Ocean) during the Holocene. Paleoceanography 20, 1-15.

Dikov, N.N., 1988. The earliest sea mammal hunters of Wrangell Island. Arctic Anthropology 25, 80-93.

Dixon, E.J., 2013. Arrows and Atl Atls: A Guide to the Archaeology of Beringia. United States Department of the Interior, National Park Service.

Draper, H.H., 1977. The aboriginal Eskimo diet in modern perspective. American Anthropologist 79, 309-316.

Dumond, D.E., 1982. Trends and traditions in Alaskan prehistory: The place of Norton culture. Arctic Anthropology 19, 39-51.

Dumond, D.E., 1987a. Prehistoric Human Occupation in Southwestern Alaska: A Study of Resource Distribution and Site Location. University of Oregon Anthropological Papers, No. 36.

Dumond, D.E., 1987b. The Eskimos and Aleuts, Revised ed. Thames and Hudson, London.

Dumond, D.E., 2001. Western Arctic Small Tool tradition, in: Perigrine, P.N., Embers, M. (Eds.), Encyclopedia of Prehistory: Arctic and Subarctic. Springer-Verlag, New York.

Dumond, D.E., 2004. Volcanism and history on the northern Alaska Peninsula. Arctic Anthropology 19, 39-51.

Erlandson, J.M., 2001. The archaeology of aquatic adaptations: Paradigms for a new millennium. Journal of Archaeological Research 9, 287-350.

Erlandson, J.M., Graham, M.H., Bourque, B.J., Corbett, D., Estes, J.A., Steneck, R.S., 2007. The kelp highway hypothesis: marine ecology, the coastal migration theory, and the peopling of the Americas. Journal of Island and Coastal Archaeology 2, 161-174.

Esdale, J.A., 2008. A current synthesis of the Northern Archaic. Arctic Anthropology 45, 3-38.

Estes, J.A., Doak, D.F., Springer, A.M., Williams, T.M., 2009. Causes and consequences of marine mammal population declines in southwest Alaska: A food-web perspective. Philosophical Transactions: Biological Sciences 364, 1647-1658.

Fretwell, S.D., Lucas, H., Jr., 1969. On territorial behavior and other factors influencing habitat distribution in birds. Acta Biotheor 19, 16-36.

Friesen, T.M., Mason, O.K. 2016. Introduction: Archaeology of the North American Arctic,in: Friesen T.M., Mason, O.K. (Eds.), The Oxford Handbook of The Prehistoric Arctic. Oxford University Press, Oxford, pp. 1-26.

Gajewski, K., Munoz, S., Peros, M., Viau, A., Morlan, R., Betts, M., 2011. The Canadian Archaeological Radiocarbon Database (CARD): Archaeological 14C dates in North America and their paleoenvironmental context. Radiocarbon 53, 371-394.

Giddings, J.L., 1964. The Archaeology of Cape Denbigh. Brown University Press, Providence, Rhode Island.

Giddings, J.L., Anderson, D.D., 1986. Beach Ridge Archaeology of Cape Krusenstern: Eskimo and PreEskimo Settlements Around Kotzebue Sound, Alaska. National Park Service,U.S. Department of the Interior, Washinton D.C.

Gilbert, M.T.P., Kivisild, T., Grønnow, B., Andersen, P.K., Metspalu, E., Reidla, M., Tamm, E., Axelsson, E., Götherström, A., Campos, P.F., Rasmussen, M., Metspalu, M., Higham, T.F.G., Schwenninger, J.L., Nathan, R., De Hoog, C.J., Koch, A., Møller, L.N., Andreasen, C., 
Meldgaard, M., Villems, R., Bendixen, C., Willerslev, E., 2008. Paleo-Eskimo mtDNA genome reveals matrilineal discontinuity in Greenland. Science 320, 1787-1789.

Grønnow, B., 1994. Qeqertassussuk - The Archaeology of a frozen Saqqaq site in Disko Bugt, west Greenland, in: Morrison, D., Pilon, J.L. (Eds.), Threads of Arctic Prehistory: Papers in Honour of William E. Taylor, Jr. Canadian Museum of Civilization, Hull, Québec, pp. 197-238.

Grønnow, B., 2016. Independece I and Saqqaq: The first Greenlanders, in: Friesen T.M., Mason, O.K. (Eds.), The Oxford Handbook of The Prehistoric Arctic. Oxford University Press, Oxford, pp. 713-736.

Gubser, N.J., 1965. The Nunamiut Eskimos: Hunters of Caribou. Yale University press, New Haven and London.

Guemple, L., 1981. Seasonal variations of the Eskimo: A study in social morphology. Marcel Mauss. American Anthropologist 83, 937-938.

Hallowell, A.I., 1926. Bear ceremonilaism in the northern Hemisphere. American Anthropologist 28, 1175.

Harper, P.E., 2007. Carbiou Management Report of Survey-Inventory Activities 1 July 2004-30 June 2006. Alaska Department of Fish and Game Division of Wildlife Conservation.

Harper, P.E., 2010. Moose Management Report of Survey-Inventory Activities 1 July 2007-30 June 2009. Alaska Department of Fish and Game, Juneau, Alaska.

Harritt, R.K., 1998. Paleo-Eskimo beginnings in North America: A new discovery at Kuzitrin Lake, Alaska. Etudes/Inuit/Studies 22, 59-81.

Haynes, T.L., Simeone, W.E., 2007. Upper Tanana Ethnographic Overview and Assessment, Wrangell St. Elias National Park and Preserve. Technical Paper No. 25. Department of the Interior, National Park Service.

Hilderbrand, G.V., Schwartz, C.C., Robbins, C.T., Jacoby, M.E., Hanley, T.A., Arthur, S.M., Servheen, C., 1999. The importance of meat, particularly salmon, to body size, population productivity, and conservation of North American brown bears. Canadian Journal of Zoology 77, 132-138.

Jazwa, C.S., Kennett, D.J., Winterhalder, B., 2013. The ideal free distribution and settlement history at Old Ranch Canyon, Santa Rosa Island, in: Jazwa, C.S., Perry, J.E. (Eds.), California's Channel Islands: The Archaeology of Human-Environment Interactions. University of Utah Press, Salt Lake City, Utah, pp. 75-96.

Jemison, L.A., Pendleton, G.W., Wilson, C.A., Small, R.J., 2006. Long-term trends in Harbor Seal numbers at Tugidak Island and Nanvak Bay, Alaska. Marine Mammal Science 22, 339-360.

Jensen, A.M., 2012. The material culture of Iñupiat whaling: an ethnographic and ethnohistorical perspective. Arctic anthropology 49, 143-161.

Jochim, M.A., 1991. Archaeology as long-term ethnography, Americn Anthropologist 93, 308-321.

Jordan, J.W., Krumhardt, A., 2003. Postglacial Climate and Vegetation of the Western Alaska Peninsula. Alaska Journal of Anthropology 1, 16-33.

Kennett, D.J., Anderson, A., Winterhalder, B., 2006. The ideal free distribution, food production, and the colonization of Oceania, in: Kennett, D.J., Winterhalder, B. (Eds.), Behavioral Ecology and the Transition to Agriculture. University of California Press, Berkeley, pp. 265-288.

Kennett, D.J., Winterhalder, B., Bartruff, J., Erlandson, J.M., 2009. An ecological model for the emergence of institutionalized social hierarchies on California's northern Channel Islands, in: Shennen, S. (Ed.), Pattern and Process in Cultural Evolution. University of California Press, Berkley, pp. 297-314.

Larsen, H., 1968. Trail Creek: Final Report on the Excavation of Two Caves on Seward Peninsula, Alaska. Acta Arctica 15, 7-79.

MacDonald, S.O., Cook, J.A., 2009. Recent Mammals of Alaska. University of Alaska Press, Fairbanks,Alaska.

Maschner, H.D.G., Knudsen, G., Benson, B., Misarti, N., 2010. The Archaeology of the Sapsuk River, Alaska. Bureau of Indian Affairs, Alaska Region Branch Regional Office. 
Mason, O.K., 1998. The Contest between the Ipiutak, Old Bering Sea, and Birnirk Polities and the origin of whaling during the first Millennium A.D. along the Bering Strait. Journal of Anthropological Archaeology 17, 240-325.

Mason, O.K., Bigelow, N.H., 2008. The crucible of early-mid Holocene climate in northern Alaska :does Northern Archaic represent the people of the spreading forest? Arctic Anthropology 45, 39-70.

Mason, O.K., Gerlach, S.C., 1995. Chukchi Hotspots, Paleo-Polynyas, and Caribou Crashes: Climatic and Ecological Dimensions of North Alaska Prehistory. Arctic Anthropology, 32, 101-130.

Mason, O.K., Jordan, J.W., 2001. Minimal late Holocene sea level rise in the Chukchi Sea: Arctic insensitivity to global change? Global and Planetary Change 32, 13-23.

Maxwell, M.S., 1980. Archaeology of the Arctic and Subarctic Zones. Annual Review of Anthropology 9, 161-185.

McCartney, A.P., Savelle, J.M., 1985. Thule Eskimo whaling in the central Canadian Arctic. Arctic Anthropology 22, 37-58.

McCartney, P.H., Helmer, J.W., 1989. Marine and terrestrial mammals in high Arctic Paleoeskimo economy. Archaeozoologica 3, 143-160.

McGhee, R., 1996. Ancient People of the Arctic. University of British Colombia, Vancouver.

Melgaard, M., 2004. Ancient Harp Seal Hunters of Disko Bay: Subsistence and Settlement at the Saqqaq Culture Site Qeqertasussuk (2400-1400 BC), West Greenland. Meddelelser om Grønland, Man and Society, Vol. 30. Danish Polar Center, Copenhagen.

Milne, S.B., Park, R.W., 2016. Pre-Dorset culture, in: Friesen T.M., Mason, O.K. (Eds.),The Oxford Handbook of The Prehistoric Arctic. Oxford University Press, Oxford, pp. 393-712.

Møbjerg, T., 1999. New adaptive strategies in the Saqqaq culture of Greenland, c. 1600-1400 BC. World Archaeology 30, 452-465.

Nelson, R.K., 1969.Hunters of the Northern Ice. University of Chicago Press, Chicago.

Nelson, R.K., 1973. Hunters of the Northern Forest: Designs for Survival among the Alaskan Kutchin. University of Chicago Press, Chicago.

Nowak, R.M., 1999. Walker's Mammals of the World, 6th ed. Johns Hopkins University Press, Baltimore.

Nowak, R.M., 2003. Walker's Marine Mammals of the World. Johns Hopkins University Press, Baltimore.

Nowaki, G., Spencer, P., Flemming, M., Brock, T., Joregenson, T., 2002. Unified ecoregions of Alaska. U.S. geological Survey Open-File Report 02-297.

O'Connell, J., Codding, B.F., 2014. Ideal Free Colonization of Australia's Arid Zone, Society for American Archaeology 79th Anuual Meeting, Austin, Texas.

Odess, D., 2005. The Arctic Small Tool Tradition Fifty Years On. Alaska Journal of Anthropology 3, 516.

Orekhov, A.A., Bland, R.L., Gokhman, A., Workman, W., Workman, K., 1998. The development of maritime adaptations among the early populations of the northwest Bering Sea region. Arctic Anthropology 35, 263-280.

Oswalt, W.H., 1976. An Anthropological Analysis of Food-Getting Technology. John Wiley \& Sons,New York.

Potter, B.A., 2008a. A first approximation of Holocene inter-assemblage variability in central Alaska. Arctic Anthropology 45, 89-113.

Potter, B.A., 2008b. Radiocarbon chronology of central Alaska; technological continuity and economic change. Radiocarbon 50, 181-204.

Powers, W.R., Jordan, R.H., 1990. Human biogeography and climate change in Siberia and arctic North America in the fourth and fifth millennia BP. Philosophical Transactions of the Royal Society of London. Series A. Mathematical and Physical Sciences 330, 665-670.

Prentiss, A.M., Walsh, M.J., Foor, T.A., Barnett, K.D., 2015. Cultural macroevolution among high latitude hunter-gatherers: a phylogenetic study of the Arctic Small Tool tradition. Journal of Archaeological Science 59, 64-79. 
Raghavan, M., DeGiorgio, M., Albrechtsen, A., Moltke, I., Skoglund, P., Korneliussen, T.S., Grønnow, B., Appelt, M., Gulløv, H.C., Friesen, T.M., Fitzhugh, W., Malmström, H., Rasmussen, S., Olsen, J., Melchior, L., Fuller, B.T., Fahrni, S.M., Stafford, T., Grimes, V., Renouf, M.A.P., Cybulski, J., Lynnerup, N., Lahr, M.M., Britton, K., Knecht, R., Arneborg, J., Metspalu, M., Cornejo, O.E., Malaspinas, A.-S., Wang, Y., Rasmussen, M., Raghavan, V., Hansen, T.V.O., Khusnutdinova, E., Pierre, T., Dneprovsky, K., Andreasen, C., Lange, H., Hayes, M.G., Coltrain, J., Spitsyn, V.A., Götherström, A., Orlando, L., Kivisild, T., Villems, R., Crawford, M.H., Nielsen, F.C., Dissing, J., Heinemeier, J., Meldgaard, M., Bustamante, C., O’Rourke, D.H., Jakobsson, M., Gilbert, M.T.P., Nielsen, R., Willerslev, E., 2014. The genetic prehistory of the New World Arctic. Science 345.

Rasic, J.T., 2008. Paleoalaskan Adaptive Strategies Viewed from Northwest Alaska.Ph.D. Dissertation, Department ofAnthropology.Washington State University.

Reeves, R.R., Stewart, B.S., Leatherwood, S., 1992. The Sierra Club Handbook of Seals and Sirenians. The Sierra Club, San Francisco.

Rick, J.W., 1987. Dates as data: An examination of the Peruvian preceramic radiocarbon record. American Antiquity 52, 55-73.

Savelle, J.M., Dyke, A.S., 2002. Variability in Palaeoeskimo occupation on south-western Victoria Island, Arctic Canada: Causes and consequences. World Archaeology 33, 508-522.

Schaaf, J.M., 2015. Report on Archeological Investigations at the Qayassiq Site (XMK-00043) Round Island, Walrus Islands State Game Sanctuary, North Bristol Bay, Alaska. Prepared for the Alaska Department of Fish and Game Division of Wildlife Conservation, and Alaska Department of Natural Resources Division of Parks and Outdoor Recreation. Office of History and Archaeology File 3420-2008, Field Archaeology Permit No. 2008-07.

Searles, E., 2002. Food and the making of modern Inuit identities. Food and Foodways 10, 55-78.

Sease, J.L., York, A.E., 2003. Seasonal distribution of Steller's Sea Lions at rookeries and haul-out sites in Alaska. Marine Mammal Science 19, 745-763.

Shirar, S., 2009. Subsistence and seasonality at a late prehistoric house pit in northwest Alaska. Journal of Ecological Anthropology 13, 6-25.

Small, R.J., Boveng, P.L., Byrd, G.V., Withrow, D.E., 2008. Harbor seal population decline in the Aleutian Archipelago. Marine Mammal Science 24, 845-863.

Stanford, D.J., 1976. The Walakpa Site, Alaska: Its Place in the Birnirk and Thule Cultures. Institution Press, Washington.

Steffian, A.F., Saltonsall, P.G., 2005. Tools but not toolkits: traces of the Arctic Small Tool tradition in the Kodiak Archipelago. Alaska Journal of Anthropology 3, 17-49.

Stephenson, R.O., Gerlach, S.C., Guthrie, R.D., Harington. C.R., Mills, R.O., Hare, G. 2001, Wood Bison in Late Holocene Alaska and adjacent Canada: paleontological, archaeological and historical records, in: Gerlach, S.C. and Murray, M.S. (Eds.), People and Wildlife in Northern North America: essays in honor of R. Dale Guthrie, pp. 124-158.

Stiner, M.C.,Munro, N.D., Surovell, T.A., 2000. The tortoise and the hare: Small-game use, the Broad-Spectrum Revolution, and Paleolithic demography. Current Anthropology 41, 39-79.

Surovell, T.A., Byrd Finley, J., Smith, G.M., Brantingham, P.J., Kelly, R., 2009. Correcting temporal frequency distributions for taphonomic bias. Journal of Archaeological Science 36, 1715-1724.

Sutherland, W.J., 1983. Aggregation and the `Ideal Free' Distribution. Journal of Animal Ecology 52, 821-828.

Tremayne, A.H., 2011. An analysis of faunal remains from a Denbigh Flint complex camp at Matcharak Lake, Alaska. Arctic Anthropology 48, 35-55.

Tremayne, A.H., 2015a. The design of Arctic Small Tool Tradition toolkits: An example from Matcharak Lake, Alaska. North American Archaeologist 36, 1-31.

Tremayne, A.H., 2015b. The Origin and Development of Maritime Foraging Systems in Northern Alaska. Ph.D.Dissertation, Department of Anthropology. University of California, Davis. 
Tremayne, A.H., 2015c. New evidence for the timing of Arctic Small Tool Tradition coastal settlement in northwest Alaska. Alaska Journal of Anthropology 13, 1-18.

Tremayne, A.H., Rasic, J.T., 2016. The Denbigh Flint complex of northern Alaska, in: Friesen T.M., Mason, O.K. (Eds.),The Oxford Handbook of The Prehistoric Arctic. Oxford University Press, Oxford, pp. 349-370.

Tushingham, S., Bettinger, R.L., 2013. Why foragers choose acorns before salmon: Storage, mobility, and risk in aboriginal California. Journal of Anthropological Archaeology 32, 527-537.

Ugan, A., Bright, J., Rogers, A., 2003. When is technology worth the trouble? Journal of Archaeological Science 30, 1315-1329.

VanderHoek, R., 2009. The Role of Ecological Barriers in the Development of Cultural Boundaries during the Later Holocene of the Central Alaska Peninsula, Anthropology. Ph.D. Dissertation, Department of Anthropology. University of Illinois at Urbana-Champaign.

Ward, G.K., Wilson, S.R., 1978. Procedures for comparing and combining radiocarbon age determinations: A critique. Archaeometry 20, 19-31.

Williams, A.N., 2012. The use of summed radiocarbon probability distributions in archaeology: a review of methods. Journal of Archaeological Science 39, 578-589.

Winterhalder, B., Kennett, D.J., Grote, M.N., Bartruff, J., 2010. Ideal free settlement of California's northern Channel Islands. Journal of Anthropological Archaeology 29, 469-490.

Workman, W.B., McCartney, A.P., 1998. Coast to coast: Prehistoric maritime cultures in the north Pacific. Arctic Anthropology 35, 361-370.

Workman, W.B., Zollars, P., 2002. The dispersal of the Arctic Small Tool Tradition into Southern Alaska: Dates and Data from the Kenai Peninsula, southcentral Alaska. Anthropological Papers of the University of Alaska 2, 39-49.

Yen, P.P.W., Sydeman, W.J., Morgan, K.H., Whitney, F.A., 2005. Top predator distribution and abundance across the eastern Gulf of Alaska: Temporal variability and ocean habitat associations. Deep Sea Research Part II: Topical Studies in Oceanography 52, 799-822.

Yesner, D.R., 1980. Maritime hunter-gatherers: ecology and prehistory. Current Anthropology 21, 727750.

Yesner, D.R., 1981. Archaeological applications of optimal foraging theory: harvest strategies of Aleut hunter-gatherers, in: Winterhalder, B., Smith, E.A. (Eds.), Hunter-Gatherer Foraging Strategies: Ethnographic and Archaeological Analyses. Univeristy of Chicago Press, Chicago, pp. 148-170.

Yesner, D.R., 1989. Moose hunters of the Boreal Forest? A re-examination of subsistence patterns in the western subarctic. Arctic 42, 97-108.

Yesner, D.R., 1998. Origins and development of maritime adaptations in the northwest Pacific region of North America: A zooarchaeological perspective. Arctic Anthropology 35, 204-222. 


\section{Figures}

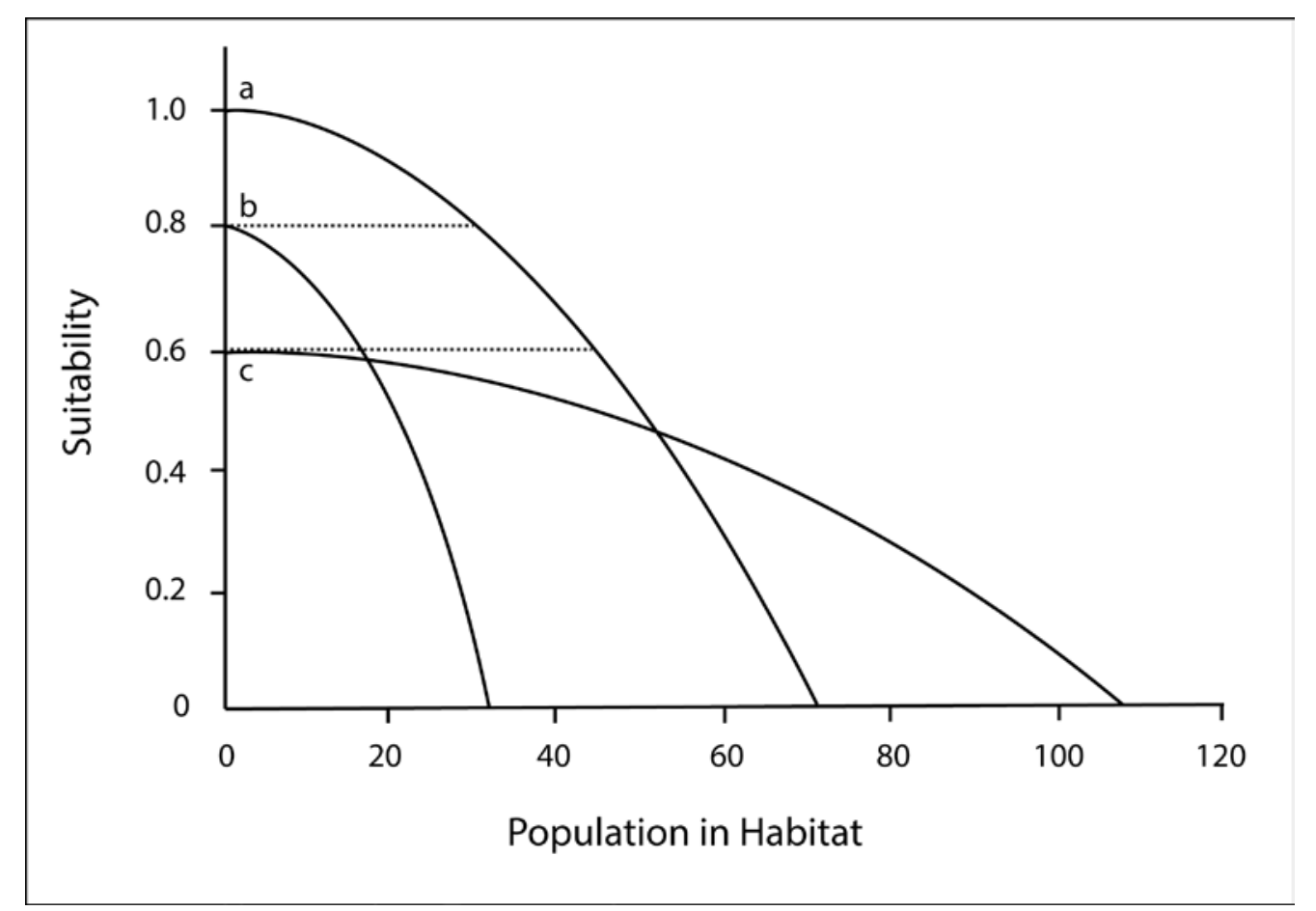

Figure1.An idealized depiction of three habitats with variable negative, density-dependent suitabilities. As population increases in habitat "a" suitability is reduced until it equals that of the uninhabited habitat "b", at which time new arrivals will distribute themselves between higher and lower ranked habitats (modified from Winterhalder et al., 2010:479). The gray-shade dotted line shows the relative distribution of population among habitats; the total population envisioned being the sum of the habitat specific populations. Note that IFD dynamics imply equalized suitabilities across habitats. 


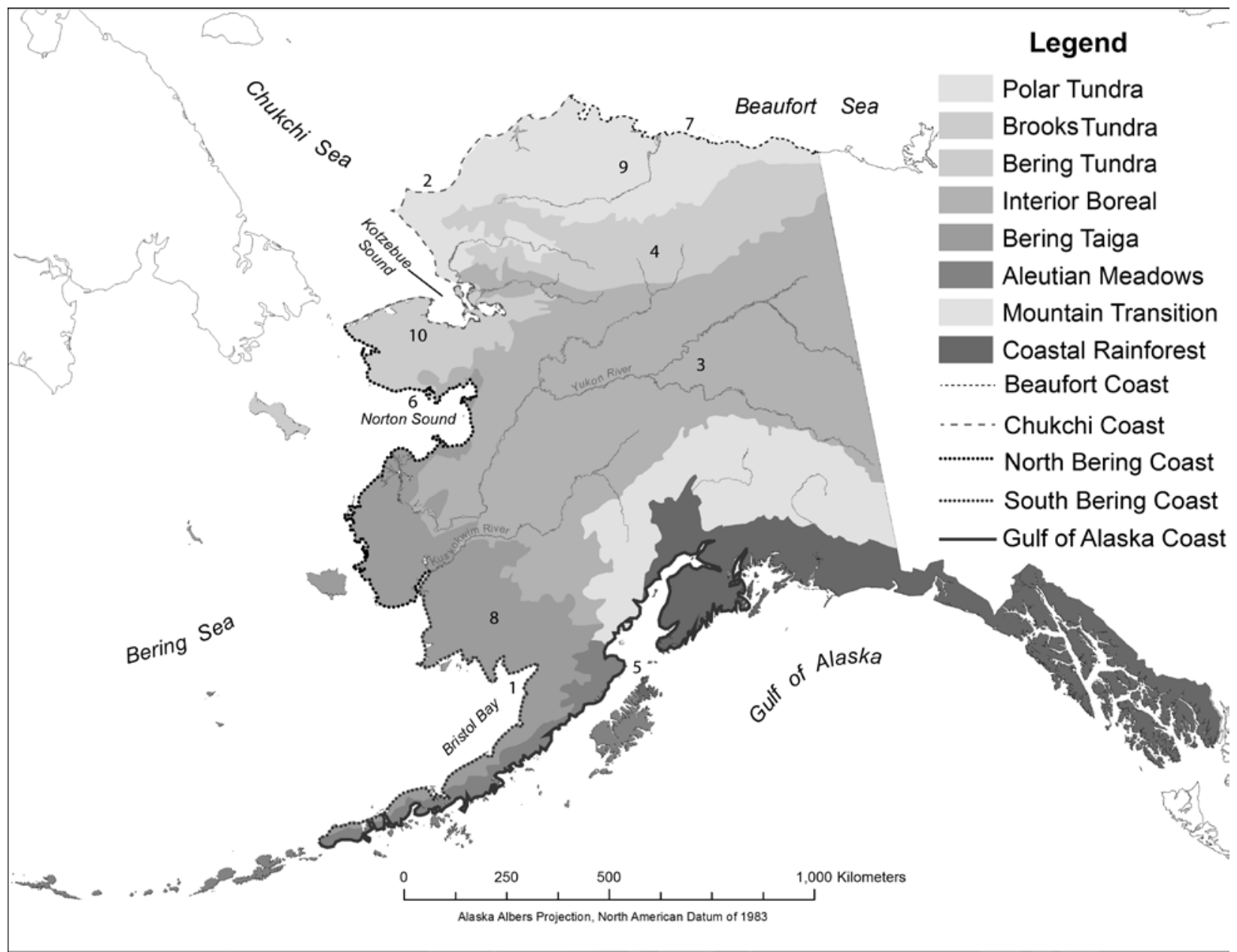

Figure2. Alaskan ecological zones used in this study. Coastal zones are defined as $10 \mathrm{~km}$ strip of land along the Bering, Chukchi and Beaufort Seas and the western Gulf of Alaska.Ecoregion boundaries were defined in ArcGIS 10.2 from Nowaki et al. (2002). The numbers indicate the IFD model rankings. 


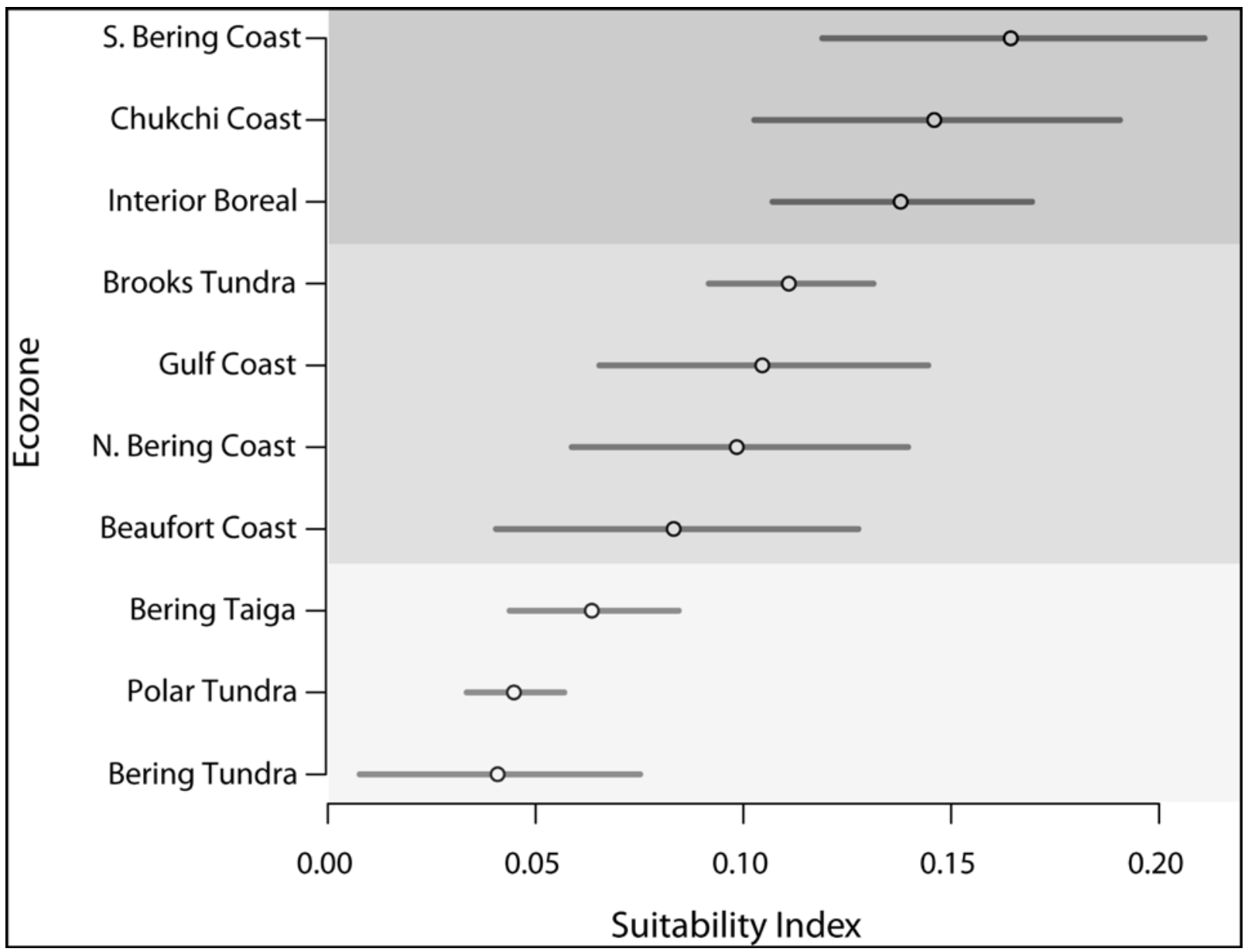

Figure 3. Overall suitability rank and uncertainty for the defined ecoregions (center mark is the mean and the bars represent uncertainty of the estimate). Data from the Year column in Table 2. 


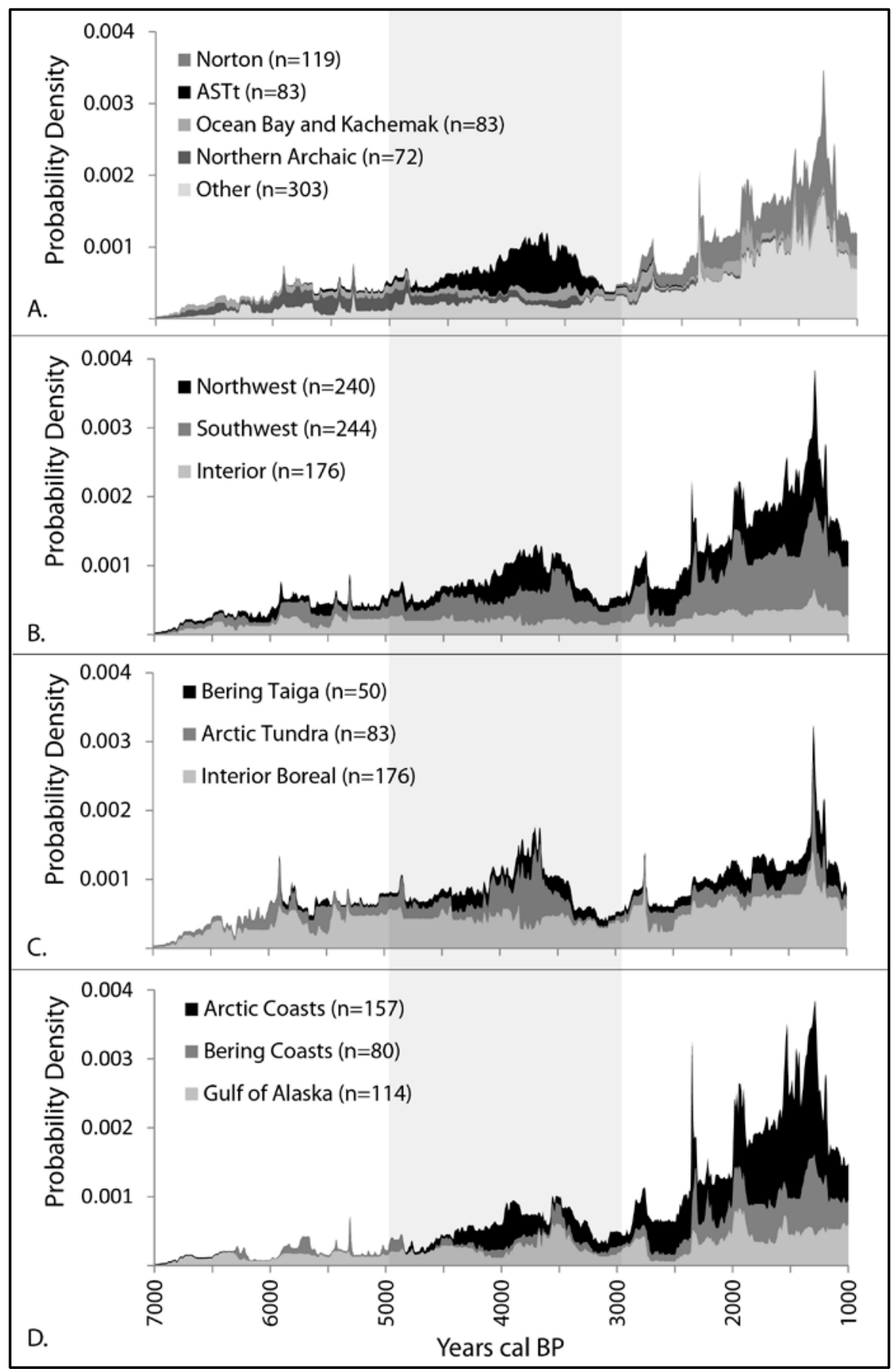

Figure 4. A. Spd plot for 660 components in Alaska during the mid-late Holocene divided proportionally by major archaeological traditions.The shaded zone indicates approximate span of the ASTt in Alaska (Supplemental Data Table 2). A mid-Holocene population increase is observed in the ASTt period.B. Spd plot divided between coastal and interior components. A shift in occupations on the coast is observed around the time the ASTt appear in Alaska. C. Spd plot for 309 interior components shows use of tundra zones fluctuated in comparison to interior boreal which supported stable population size throughout. D. Spd plot of 351 coastal components showing use of Bering and Arctic coasts increased dramatically in the late Holocene while the Gulf of Alaska was occupied earliest and most continuously. 


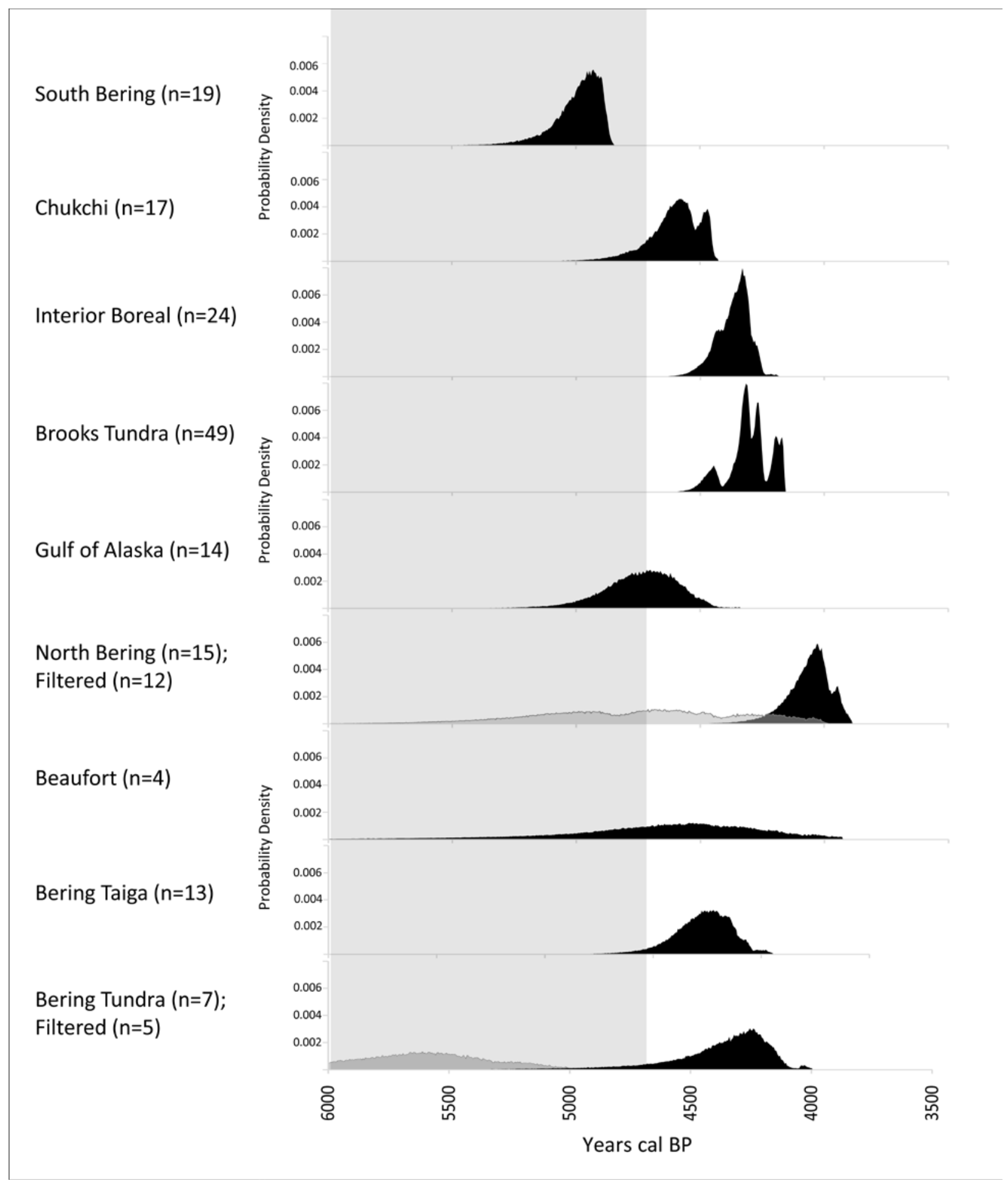

Figure 5. Probability density plots showing the modeled start dates for ASTt settlement per ecoregion. The shaded area indicates the earliest modeled dates are from the coast. The gray density curves include the suspect dates from Iyatayet (NOB-002) and Kuzitrin Lake (BEN-053), which show very high uncertainty around the modeled start date.(Note there are not enough ASTt dates from the polar tundra to build a model). 


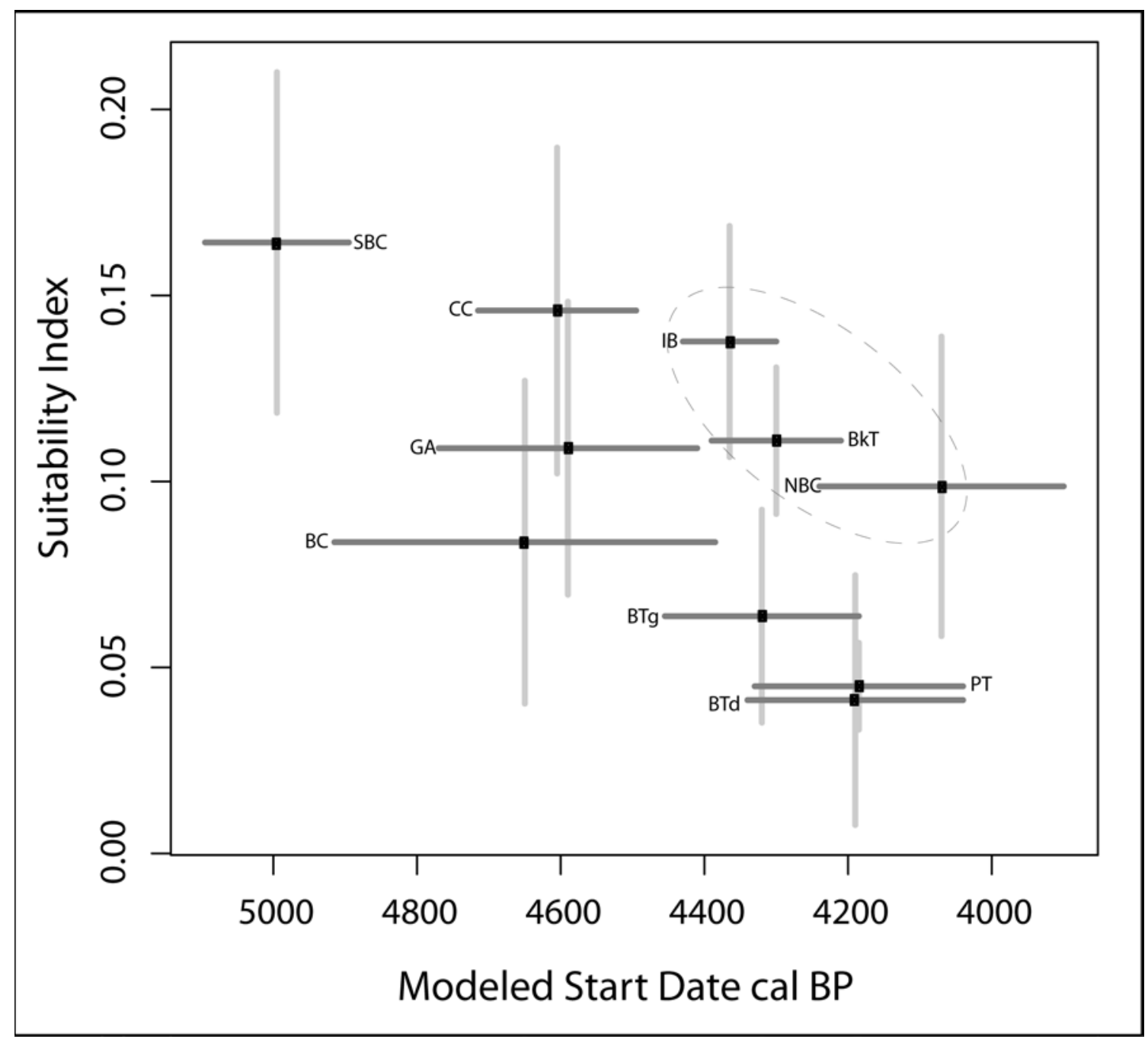

Figure6. Bivariate plot showing earliest modeled ASTt start date mean and standard deviation against suitability index for each ecoregion in Alaska. The ecoregions indicated by the circled area were settled later than predicted (see text).1. South Bering Coast; 2. Chukchi Coast; 3. Interior Boreal; 4. Brooks Tundra; 5. Gulf of Alaska Coast; 6. North Bering Coast; 7. Beaufort Coast; 8. Bering Taiga; 9. Polar Tundra; 10. Bering Tundra. 


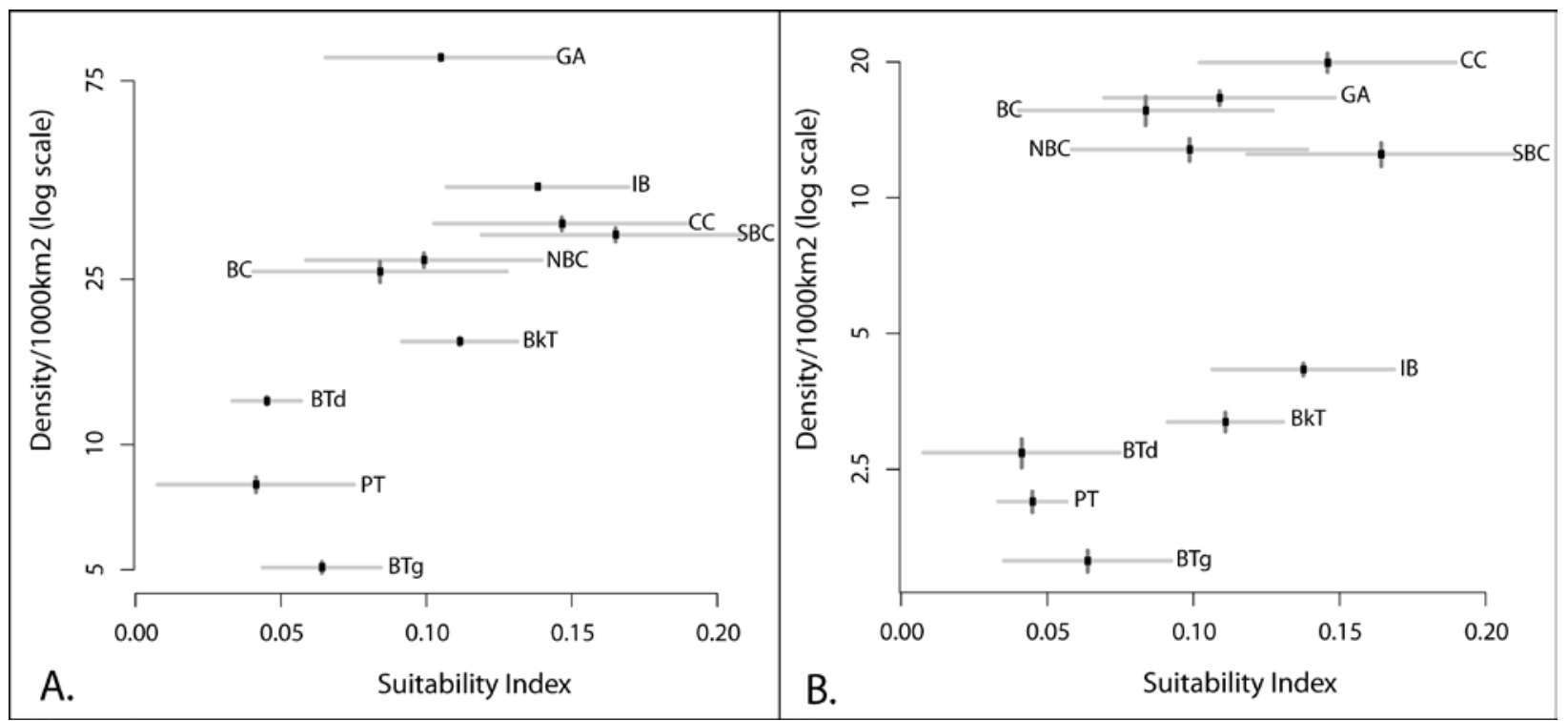

Figure 7. A. Site density verses suitability index for 22,850 Alaska sites from all time periods. B. Site density verses suitability index for 4379 mid-late Holocene sites with ascribed cultural affiliation. (See Figure 6 for key). 


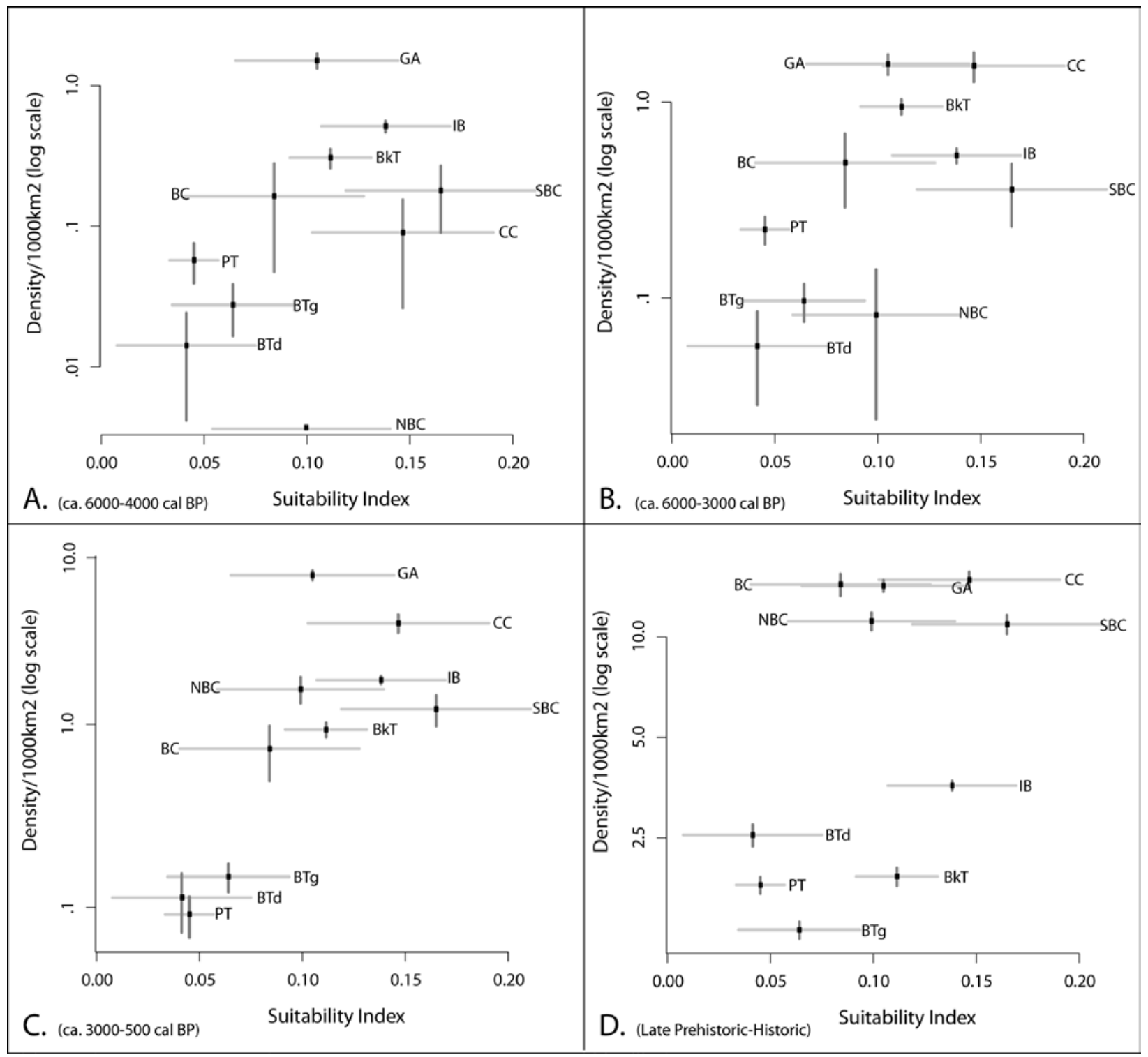

Figure 8. Bivariate plots showing site densities by ecoregion for cultures present in Alaska during the mid-late Holocene.A. Includes Northern Archaic and Ocean Bay site counts B. Includes Northern Archaic, Ocean Bay and ASTt site counts; C. Includes Choris, Norton, Kachemak, Northern Maritime, and Prehistoric Athabaskan site counts. D. Incudes sites from the Late Prehistoric to Historic period. A clear trend showing greater site density in higher ranked habitats is observed across all periods of the mid-late Holocene with an increase in occupations observed in lower ranked habitats in the late Prehistoric-Historic period.(See Figure 6 for key). 


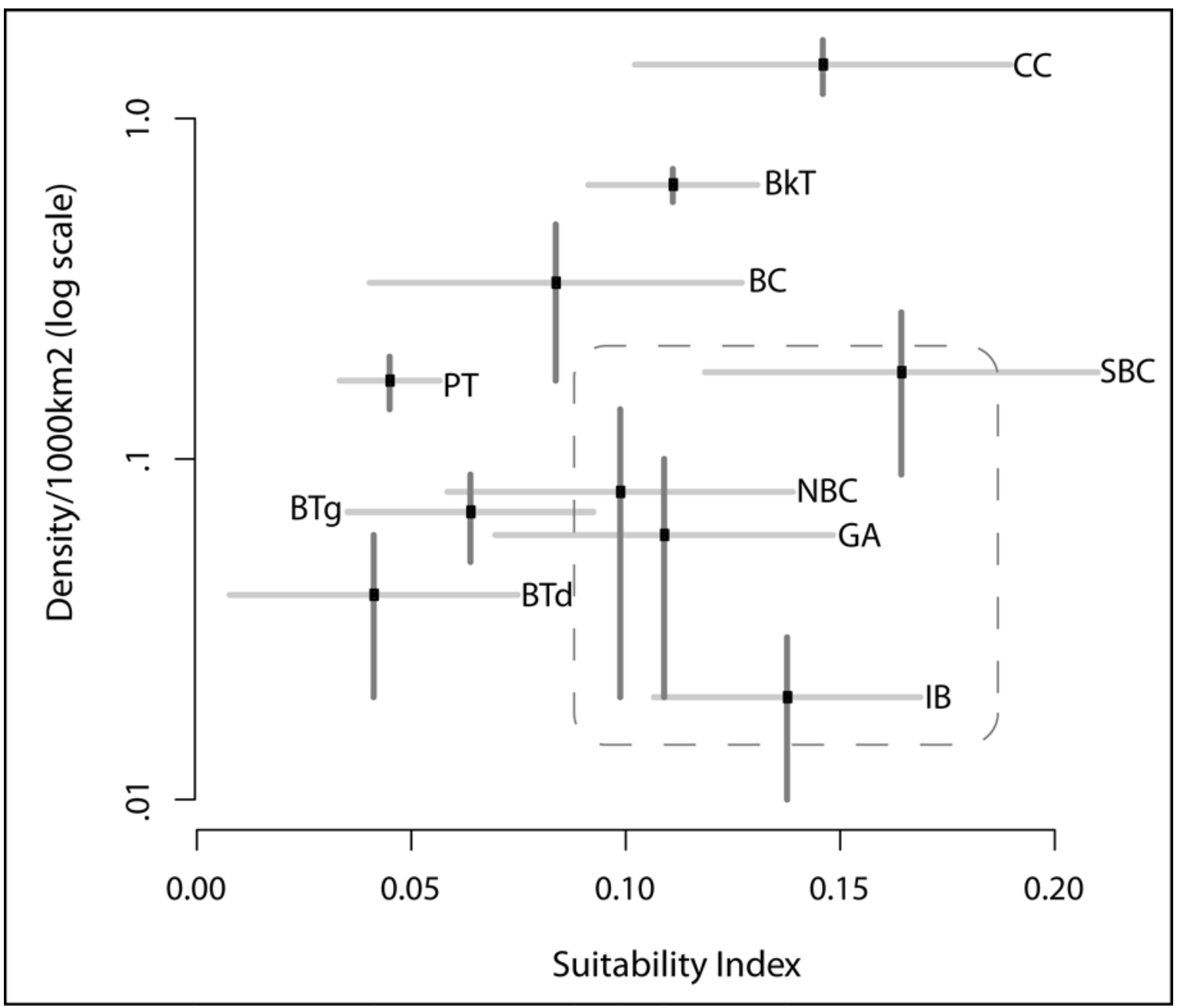

Figure9. A bivariate plot of ASTt site density per $1000 \mathrm{~km}^{2}$ verses the suitability index of animal biomass. Circled area shows ecoregions that have lower ASTt site densities than expected (see text). (See Figure 6 for key). 


\section{Tables}

Table 1. Average body mass for all large mammals in Alaska used in this study (AKF\&G 2014; Nowack, 1999, 2003; Reeves et al. 1992).

\begin{tabular}{lccccc}
\hline Taxa & \multicolumn{5}{c}{ Average Weight (kg) } \\
\hline Marine & Male/High & Female/Low & Average & $\underline{\text { S.D. }}$ & $\underline{\underline{\text { Seasonal }}}$ \\
\cline { 2 - 5 } Beluga (D. leucas) & 1500.0 & 1360.0 & 1430.0 & 17.5 & 1430.0 \\
Harbor Porpoise (P. phocoena) & 125.0 & 80.0 & 102.5 & 5.6 & 102.5 \\
Walrus (O. rosmarus) & 1700.0 & 400.0 & 1050.0 & 162.5 & 1050.0 \\
Bearded seal (E. barbatus) & 360.0 & 200.0 & 280.0 & 20.0 & 224.0 \\
Ringed seal (P. hispida) & 70.0 & 50.0 & 60.0 & 2.5 & 51.0 \\
Spotted seal (P. largha) & 123.0 & 82.0 & 102.5 & 5.1 & 87.0 \\
Ribbon seal (P. fasciata) & 95.0 & 85.0 & 90.0 & 1.3 & 76.0 \\
Harbor seal (P. vitulina) & 170.0 & 50.0 & 110.0 & 15.0 & 93.0 \\
Stellar sea lion (E. jubatus) & 1120.0 & 350.0 & 735.0 & 96.3 & 624.8 \\
Sea otter (E. lutris) & 45.0 & 15.0 & 30.0 & 3.8 & 30.0 \\
Terrestrial & & & & & \\
Wood bison (B. bison) & 1000.0 & 350.0 & 675.0 & 81.3 & 607.5 \\
Moose (A. alces) & 825.0 & 200.0 & 512.5 & 78.1 & 461.3 \\
Musk ox (O. moschatus) & 410.0 & 200.0 & 305.0 & 26.3 & 274.5 \\
Caribou (R. tarandus) & 170.5 & 100.0 & 135.3 & 8.8 & 121.7 \\
Dallsheep (O. dalli) & 136.0 & 68.0 & 102.0 & 8.5 & 92.0 \\
Mountain Goat (O. americanus) & 140.0 & 46.0 & 93.0 & 11.8 & 83.7 \\
Polar bear (U. maritimus) & 500.0 & 150.0 & 325.0 & 43.8 & 292.5 \\
Brown bear (U. arctos) & 600.0 & 100.0 & 350.0 & 62.5 & 315.0 \\
Black bear (U. americanus) & 270.0 & 92.0 & 181.0 & 22.3 & 163.0 \\
\hline
\end{tabular}


Table 2.Suitability index values and standard deviations for each ecological zone by season and averaged over the year.

\begin{tabular}{lcccccccccc}
\hline Ecoregion & Winter & SD & Spring & SD & Summer & SD & Fall & SD & Year & SD \\
\hline S. Bering Coast & 0.25 & 0.06 & 0.15 & 0.05 & 0.14 & 0.04 & 0.14 & 0.04 & 0.16 & 0.05 \\
Chukchi Coast & 0.13 & 0.06 & 0.14 & 0.04 & 0.12 & 0.03 & 0.18 & 0.04 & 0.15 & 0.04 \\
Interior Boreal & 0.15 & 0.05 & 0.13 & 0.03 & 0.14 & 0.03 & 0.13 & 0.03 & 0.14 & 0.03 \\
Brooks Tundra & 0.06 & 0.02 & 0.15 & 0.02 & 0.06 & 0.01 & 0.15 & 0.02 & 0.11 & 0.02 \\
Gulf Coast & 0.08 & 0.03 & 0.12 & 0.04 & 0.12 & 0.04 & 0.11 & 0.04 & 0.11 & 0.04 \\
N. Bering Coast & 0.10 & 0.07 & 0.10 & 0.04 & 0.09 & 0.03 & 0.10 & 0.04 & 0.10 & 0.04 \\
Beaufort Coast & 0.05 & 0.02 & 0.08 & 0.05 & 0.13 & 0.05 & 0.07 & 0.04 & 0.08 & 0.04 \\
Bering Taiga & 0.09 & 0.05 & 0.06 & 0.02 & 0.06 & 0.02 & 0.06 & 0.02 & 0.06 & 0.03 \\
Polar Tundra & 0.01 & 0.01 & 0.03 & 0.01 & 0.12 & 0.02 & 0.02 & 0.01 & 0.04 & 0.01 \\
Bering Tundra & 0.08 & 0.07 & 0.03 & 0.02 & 0.03 & 0.02 & 0.03 & 0.02 & 0.04 & 0.03 \\
\hline
\end{tabular}


Table 3.Modeled start dates for ASTt dispersal and settlement in each ecoregion in Alaska.

\begin{tabular}{llcl}
\hline Ecoregions & Oldest $^{\mathbf{1 4}} \mathbf{C}$ Date & ASTt Dates (n) & Modeled Start Date cal BP \\
\hline S. Bering Coast & $4390 \pm 40$ & 19 & $4995 \pm 100(3260-2905 \mathrm{BC})$ \\
Chukchi Coast & $4100 \pm 40$ & 17 & $4605 \pm 110(2880-2490 \mathrm{BC})$ \\
Interior Boreal & $3966 \pm 38$ & 24 & $4365 \pm 65(2555-2300 \mathrm{BC})$ \\
Brooks Tundra & $4420 \pm 430$ & 44 & $4300 \pm 90(2400-2210 \mathrm{BC})$ \\
Gulf Coast & $4220 \pm 110$ & 14 & $4590 \pm 180(2840-2540 \mathrm{BC})$ \\
N. Bering Coast (1) & $4655 \pm 214$ & 15 & $4750 \pm 430(3570-2050 \mathrm{BC})^{\mathrm{a}}$ \\
N. Bering Coast (2) & $3717 \pm 39$ & 12 & $4070 \pm 170(2310-1940 \mathrm{BC})^{\mathrm{a}, \mathrm{b}}$ \\
Beaufort Coast & $4060 \pm 130$ & 7 & $4650 \pm 265(3325-2300 \mathrm{BC})$ \\
Bering Taiga & $3900 \pm 130$ & 13 & $4320 \pm 135(2645-2095 \mathrm{BC})$ \\
Bering Tundra (1) & $4770 \pm 260$ & 7 & $5760 \pm 500(6690-4950 \mathrm{BC})$ \\
Bering Tundra (2) & $3810 \pm 65$ & 5 & $4190 \pm 150(2550-1940 \mathrm{BC})^{\mathrm{b}}$ \\
Polar Tundra & $3850 \pm 100$ & 1 & $4185 \pm 145(2530-2040 \mathrm{BC})^{\mathrm{c}}$ \\
\hline \multicolumn{2}{c}{${ }^{\mathrm{a}}$ Averaged split samples; ${ }^{\mathrm{b}}$ suspect dates were rejected; ${ }^{\mathrm{c}}$ Not modeled, calibrated date only. }
\end{tabular}


Table 4.Site counts and densities (in parentheses) per $1000 \mathrm{~km}^{2}$ by ecoregion and culture. Site density equals count divided by total area for each ecoregion.NA = Northern Archaic; OB/K = Ocean Bay \& Kachemak; AST = Arctic Small Tool tradition; C/N = Choris \& Norton; NM = Northern Maritime tradition; INU/ALQ = Inuit \& Alutiiq; ATH= Athabaskan (divided between prehistoric and historic). Total 1 includes mid-late Holocene site counts with known cultural affiliation. Total 2 includes every site from the study area in AHRS regardless of time period.

\begin{tabular}{lcccccccccccc}
\hline Ecoregions & $\begin{array}{c}\text { Area } \\
\mathbf{1 0 0 0 K m}\end{array}$ & NA & OB & AST & KT & NT & NM & $\begin{array}{c}\text { Pre- } \\
\text { ATH }\end{array}$ & INU/ALQ & $\begin{array}{c}\text { His- } \\
\text { ATH }\end{array}$ & Total 1 & Total 2 \\
\hline S. Bering Coast & 22.3 & $3(0.1)$ & $1(0.0)$ & $4(0.2)$ & $0(0.0)$ & $22(1.0)$ & $5(0.2)$ & $0(0.0)$ & $244(10.9)$ & $0(0.0)$ & $279(12.5)$ & $714(31.9)$ \\
Chukchi Coast & 22.2 & $2(0.1)$ & $0(0.0)$ & $32(1.4)$ & $0(0.0)$ & $40(1.8)$ & $39(1.8)$ & $0(0.0)$ & $329(14.8)$ & $0(0.0)$ & $442(19.9)$ & $754(34.2)$ \\
Interior Boreal & 243.4 & $124(0.5)$ & $1 / 0.0)$ & $5(0.0)$ & $0(0.0)$ & $7(0.0)$ & $3(0.0)$ & $414(1.7$ & $184(0.8)$ & $689(2.8)$ & $1427(4.2)$ & $10142(41.7)$ \\
Brooks Tundra & 133.8 & $41(0.3)$ & $0(0.0)$ & $86(0.6)$ & $0(0.0)$ & $35(0.3)$ & $8(0.1)$ & $82(0.6)$ & $193(1.4)$ & $63(0.5)$ & $508(3.2)$ & $2370(17.7)$ \\
Gulf Coast & 58.2 & $0(0.0)$ & $70(1.5)$ & $3(0.1)$ & $212(4.6)$ & $6(0.1)$ & $0(0.0)$ & $85(1.8)$ & $663(14.2)$ & $262(5.6)$ & $1301(13.3)$ & $3975(85.3)$ \\
N. Bering Coast & 24.5 & $0(0.0)$ & $0(0.0)$ & $2(0.1)$ & $0(0.0)$ & $5(0.2)$ & $33(1.3)$ & $0(0.0)$ & $273(11.2)$ & $0(0.0)$ & $313(12.8)$ & $680(27.8)$ \\
Beaufort Coast & 12.2 & $2(0.2)$ & $0(0.0)$ & $4(0.3)$ & $0(0.0)$ & $4(0.3)$ & $5(0.4)$ & $0(0.0)$ & $176(14.4)$ & $0(0.0)$ & $191(15.6)$ & $319(26.1)$ \\
Bering Taiga & 154.0 & $6(0.0)$ & $0(0.0)$ & $15(0.1)$ & $0(0.0)$ & $26(0.1)$ & $6(0.0)$ & $0(0.0)$ & $288(1.3)$ & $2(0.0)$ & $343(2.5)$ & $1103(5.1)$ \\
Polar Tundra & 174.5 & $10(0.1)$ & $0(0.0)$ & $29(0.2)$ & $0(0.0)$ & $12(0.1)$ & $4(0.0)$ & $0(0.0)$ & $315(1.8)$ & $0(0.0)$ & $370(2.1)$ & $2223(12.7)$ \\
Bering Tundra & 70.6 & $1(0.0)$ & $0(0.0)$ & $3(0.0)$ & $0(0.0)$ & $7(0.1)$ & $1(0.0)$ & $0(0.0)$ & $180(2.5)$ & $0(0.0)$ & $192(2.7)$ & $566(8.0)$ \\
Total & & $\mathbf{1 8 9}$ & $\mathbf{7 2}$ & $\mathbf{1 8 3}$ & $\mathbf{2 1 2}$ & $\mathbf{1 6 4}$ & $\mathbf{1 0 4}$ & $\mathbf{5 8 1}$ & $\mathbf{2 4 0 2}$ & $\mathbf{1 0 1 6}$ & 5366 & 22850 \\
\hline
\end{tabular}

